Illinois State University

ISU ReD: Research and eData

Theses and Dissertations

$9-7-2014$

\title{
Influence Of Seductive Details, Belief-Congruence, And Repeated Testing On Memory For Controversial Information
}

Daniel Adam Nuccio

Illinois State University, danielnuccio@yahoo.com

Follow this and additional works at: https://ir.library.illinoisstate.edu/etd

Part of the Cognitive Psychology Commons, and the Social Psychology Commons

\section{Recommended Citation}

Nuccio, Daniel Adam, "Influence Of Seductive Details, Belief-Congruence, And Repeated Testing On Memory For Controversial Information" (2014). Theses and Dissertations. 251.

https://ir.library.illinoisstate.edu/etd/251

This Thesis is brought to you for free and open access by ISU ReD: Research and eData. It has been accepted for inclusion in Theses and Dissertations by an authorized administrator of ISU ReD: Research and eData. For more information, please contact ISUReD@ilstu.edu. 


\title{
INFLUENCE OF SEDUCTIVE DETAILS, BELIEF-CONGRUENCE, AND REPEATED TESTING ON MEMORY FOR CONTROVERSIAL INFORMATION
}

\author{
Daniel A. Nuccio
}

66 Pages

December 2014

People often encounter conflicting information on a wide array of topics. How they evaluate this information in relation to their current beliefs, and the effects of other influences, such as the weight given to superficial aspects of the information (e.g., pictures, anecdotes, or jargon that are at most minimally related to an author's argument), has been of interest to researchers for many years. One component of their processing and evaluation of this information is their memory for the information. This study set out to examine the following questions: (1) Is belief-congruent information remembered better or worse than belief incongruent information? (2) Does the addition of superficial scientific information to belief-congruent or belief-incongruent information influence how well the newly presented information is remembered? (3) Does repeated testing have an effect on memory for the information? (4) Do any of these factors elicit a greater number of memory intrusions in a free recall task? 
INFLUENCE OF SEDUCTIVE DETAILS, BELIEF-CONGRUENCE, AND REPEATED TESTING ON MEMORY FOR

CONTROVERSIAL INFORMATION

DANIEL A. NUCCIO

A Thesis Submitted in Partial Fulfillment of the Requirements for the Degree of

MASTER OF SCIENCE

Department of Psychology

ILLINOIS STATE UNIVERSITY

2014 
Copyright 2014 Daniel A. Nuccio 
INFLUENCE OF SEDUCTIVE DETAILS, BELIEF-CONGRUENCE, AND REPEATED TESTING ON MEMORY FOR CONTROVERSIAL INFORMATION

DANIEL A. NUCCIO

COMMITTEE MEMBERS:

Steve Croker, Chair

Eric D. Wesselmann 


\section{CONTENTS}

Page

CONTENTS

TABLES

FIGURES

CHAPTER

I. REVIEW OF RELATED LITERATURE 1

Introduction 1

Seductive Details $\quad 2$

Motivated Reasoning $\quad 4$

Memory 13

Theoretical Explanations 18

II. STUDY OVERVIEW 21

III. METHODS 25

Participants $\quad 25$

Revised Paranormal Belief Scale (R-PBS) 26

Rational-Experiential Inventory 26

Texts and Scoring $\quad 27$

Procedure 28

IV. STATISTICAL ANALYSES 31

$\begin{array}{lll}\text { V. RESULTS } & 34\end{array}$

$\begin{array}{ll}\text { VI. DISCUSSION } & 41\end{array}$

Seductive Details 41

Belief-Congruence $\quad 42$

Repeated Testing 45 
Memory Intrusions

REFERENCES

APPENDIX A: Revised Paranormal Belief Scale (R-PBS; Tobacyk 2004)

APPENDIX B: Rational Experiential Belief Inventory (REI; Pacini \& Epstein, 1999) 57

APPENDIX C: Supports without Neurocognitive Jargon

APPENDIX D: Refutes without Neurocognitive Jargon

APPENDIX E: Supports with Neurocognitive Jargon

APPENDIX F: Refutes with Neurocognitive Jargon

APPENDIX G: Supports without Neurocognitive Jargon (with Idea Units)

APPENDIX H: Refutes without Neurocognitive Jargon (with Idea Units)

APPENDIX I: Supports with Neurocognitive Jargon (with Idea Units)

APPENDIX J: Refutes with Neurocognitive Jargon (with Idea Units) 


\section{TABLES}

Tables $\quad$ Page

1. Descriptive Statistics for Time 1 Recall 35

2. Descriptive Statistics for Recall, Time 1 and 2

3. Descriptive Statistics for Intrusions, Time 1 39 


\section{FIGURES}

Figures $\quad$ Page

1. Distribution of R-PBS Total 32

2. Influence of Paranormal Belief on Time 1 Recall 35

3. Influence of Seductive Details on Time 1 Recall 37

4. Influence of Seductive Details with Time 37

5. Influence of Time on Recall 38

6. The Influence of Seductive Details on Time 1 Memory Intrusions 39

7. Influence of Valence on Time 1 Recall 40 


\section{CHAPTER I}

\section{REVIEW OF RELATED LITERATURE}

\section{Introduction}

People commonly encounter conflicting information on a wide array of topics. This information can relate to any number of political, scientific, or social issues.

Sometimes this information can be on contentious political topics such as abortion or the deterrent effects of the death penalty. Other times it can be of a scientific nature, dealing with issues such as evolution or whether direct instruction is a superior teaching method to discovery learning. These topics may be of high importance to an individual, such as whether daycare is as good for a young child as home care by a parent. Alternatively, these topics may be of low importance to an individual, such as whether increased risktaking behavior in firemen leads to better job performance. How people evaluate such conflicting information, and the resilience of people's conclusions once they are formed, have been of interest to cognitive, social psychological, and educational researchers for many years, and have recently captured the attention of several neuroscientists. What such researchers often find is that people use numerous heuristics, or cognitive shortcuts, when evaluating such information.

Oftentimes these cognitive shortcuts are thought of in terms of the general population's failure to apply or understand concepts relating to statistics and probability when making decisions or judgments concerning uncertain events. These shortcuts can be 
broken down into heuristics relating to representativeness, availability, and anchoring (Tversky \& Kahneman, 1974). Yet, in a broader sense, one can also include additional factors that have been shown to influence how people make decisions and evaluate information. Among the well-established factors within social psychology are commitment and consistency, reciprocity, social proof, liking, authority, and scarcity (Cialdini, 1984; 1993). However, other factors have been examined as well. These include the value attributed to seductive details, which in some cases may serve as a proxy for authority as may be the case in instances of superficial yet meaningless scientific information (Weisberg, Keil, Goodstein, Rawson, \& Gray, 2008), and biases due to one's current beliefs, desires, or opinions. Such factors as those mentioned above appear to not only be found in undergraduate college students and adult participants that respond to ads in a paper - the two groups that usually provide the data for such research but also those with advanced levels of education, such as law students and graduate students in political science presented with new information for controversial topics outside their respective areas of expertise (Wiley, 2005), as well as those that have been trained to think analytically and scientifically, such as medical school faculty, research psychologists, and students in advanced level cognitive science courses (Reich et al., 2006; Weisberg et al., 2008; Wilson et al., 1993).

\section{Seductive Details}

Interesting or entertaining pieces of information with little if any relevance to the theme, topic, or point of the information being presented can affect the evaluation of new information. These kinds of additions to information are known as seductive details 
(Harp \& Mayer, 1998; Weisberg et al., 2008). Presumably seductive details work by priming individuals to organize what they are about to learn around irrelevant prior knowledge (Harp \& Mayer, 1998), by disrupting the deeper processing necessary to organize and integrate new information into a coherent mental model (Mayer, Griffith, Jurkowitz, \& Rothman, 2008), or by some combination of the above. Regardless though, their general effects are as follows: they make people perceive information as more interesting (Weisberg et al., 2008), despite decreasing their retention for the material (Harp \& Mayer, 1998), as well as their ability to apply the newly learned information (Harp \& Mayer, 1998; Mayer, et al., 2008).

For example, by adding information about lightning related deaths to a passage on how lightning occurs, Harp and Mayer (1998) demonstrated that seductive details could decrease memory for relevant information and the ability of individuals to answer critical thinking questions pertaining to the material, such as the relationship between temperature and lightning or why lightning may be absent despite the presence of clouds. These effects were not mitigated by such study aids as the highlighting of relevant passages or providing participants with a list of learning objectives. In a related study, Weisberg et al., (2008) showed that by adding irrelevant neuroscientific information, which arguably carries a greater air of authority, to a weak explanation for psychological phenomena, they could elicit higher satisfaction for the weak explanation from individuals without any training in psychology or neuroscience, as well as from individuals in an intermediate level cognitive neuroscience class.

However, other studies do suggest that the effects of seductive details may be more complicated than simply whether they are present or absent. Most notably, the 
putative detrimental effect of seductive details on memory is not always found (Mayer et al., 2008; Rowland et al., 2008). In a pair of experiments in which participants were presented with information on viruses or the digestive system, seductive details concerning the effect of sex on the immune system or how to safely swallow a sword were found to decrease subsequent problem solving ability for questions related to viruses and the digestive system respectively, but had no influence on retention for those topics (Mayer et al., 2008). One possible reason for why the negative effects of seductive details on memory are not always found may have to do with the placement of the seductive details. This has been indicated by Rowland et al. (2008), who found that seductive details in the form of fabricated stories about Sigmund Freud wetting his bed, having trouble with women, and having a subtly Oedipal relationship with his mother, only decreased memory for information about his psychosexual stages of development if this unrelated information was presented early in a text on the Freudian psychosexual stages of development as opposed to late in the text.

\section{Motivated Reasoning}

Additionally, what researchers often find is that people seldom process information independently of their beliefs (Boysen \& Vogel, 2007; Boysen \& Vogel, 2008; Corner, Whitmarsh, \& Xenias, 2012; Harris, Sheth, \& Cohen, 2007; Hastorf \& Cantril, 1954; Jones \& Russell, 1980; Levine \& Murphy, 1943; Lord, Lepper, \& Preston, 1984; Lord, Ross, \& Lepper 1979; Plous 1991; Westen, Blagov, Harenski, Kilts, \& Hamann, 2006) or personal motivations (Bastardi, Uhlman, \& Ross, 2011). Instead, what such research demonstrates is that people often evaluate information in a biased manner. 
Generally, many people seem to experience some kind of inherent cognitive difficulty in evaluating new information in an unbiased manner (Anderson, Lepper, \& Ross, 1980; Bastardi, Uhlman, \& Ross, 2011; Boysen \& Vogel, 2007; Boysen \& Vogel 2008; Corner et al., 2012; Jones \& Russell, 1980; Levine \& Murphy, 1943; Lord et al., 1984; Lord et al., 1979 1979; Masnick \& Zimmerman, 2009; Munro, Leary, \& Lasane, 2004; Munro 2010; Plous, 1991; Reich, Green, Brock, \& Tetlock, 2006; Russell \& Jones, 1980; Wilson, DePaulo, Mook, \& Klaaren, 1993), and may in fact work unknowingly to distort evidence that conflicts with their beliefs, or misremember what their beliefs were prior to encountering conflicting evidence as a means to better align evidence and belief (Jones \& Russell, 1980; Kuhn, 1989; Munro, Leary, \& Lasane, 2004), even when explicitly instructed to attempt to be unbiased (Lord et al., 1984). Some of the factors that influence information processing include personal biases due to current beliefs (Boysen \& Vogel, 2007; Boysen \& Vogel, 2008; Corner et al ., 2012; Jones \& Russell, 1980; Levine \& Robinson, 1943; Lord, et al., 1984; Lord et al., 1979; Munro et al., 2004; Plous, 1991), perceived importance (Reich et al., 2006; Wilson et al., 1993), personal motivation (Bastardi, Uhlman, \& Ross, 2011), and just being asked to form an opinion on a topic (Anderson, Lepper, \& Ross 1980; Masnick \& Zimmerman, 2009).

It has often been shown that when new information is consistent with an individual's current beliefs, biases, and desires, it will be rated more positively compared to when it is not (Bastardi Uhlman, \& Ross, 2011; Corner et al., 2012; Lord et al., 1979; Munro et al., 2004). This can mean people will rate it as more obvious, more valid, more publishable, or having been attained through better methods (Bastardi, Uhlman, \& Ross, 
2011; Corner et al., 2012; Lord et al., 1979; Masnick \& Zimmerman, 2009; Reich et al., 2006; Wilson et al., 1993).

But why are people, including those who are presumably well educated or trained to think more rationally or scientifically than the general population, so prone to such cognitive mistakes when evaluating new information? Broadly speaking, it is because information, scientific or not, is seldom processed in an intellectual vacuum. According to Levine and Murphy (1943), how one perceives and learns is highly influenced by a personal frame of reference shaped by an individual's values, needs, and desires. Hastorf and Cantril (1954) have argued that people selectively attend to, perceive, and remember events from their environment as they are relevant to them, the observer/processor. Lord et al. (1979) even suggest that individuals will routinely discredit or discount information that contradicts a currently held belief and deem information of little or no probative value if it does not support one's view. In addition, they propose that when new information is mixed or inconclusive, people of opposite views may assimilate it with their current beliefs even when the content of the information does not warrant doing so.

Lord et al. (1979) investigated some of these ideas, in which participants with strong views concerning the deterrent effects of the death penalty were presented with the flawed conclusions of two fictitious studies with contradictory results. Participants in this study first received the conclusion of one fictitious study, followed by a questionnaire to evaluate the changes in their attitudes on the deterrent effects of the death penalty. They were then given further details about the fictitious study, as well as criticisms and rebuttals, which they were asked to evaluate. Once the evaluation was complete, they received the conclusion of a second fictitious study that came to the opposite conclusion, 
and were put through the same procedure as they were for the first one. What was found was that despite a momentary effect of "evidence" disconfirming their initial beliefs, people evaluated the fictitious studies that agreed with their initial beliefs as more convincing and better conducted; it was also found that inconclusive or mixed data could lead to a greater polarization in one's beliefs, although later research has indicated that such arguably value-neutral information may have a stronger influence on those who already hold an extreme position (Boysen \& Vogel, 2007).

Personal motivation has been shown to influence how people process new information through similar methods. In an experiment on how one's motivations may alter how one interprets the results of a scientific study, Bastardi et al., (2011) gave couples likely to have children in the near future descriptions of two fictitious studies on the effects of daycare and home care on the development of children. One fictitious study concluded daycare had better effects on the development of children; the other fictitious study indicated home care had better effects on the development of children. Prior to participating in the study, the couples involved were preselected based on whether or not they planned to put their future child in daycare. Half the couples involved had already decided that one parent would remain at home with their future child; half were conflicted about whether one parent should stay home or if their future child should be sent to daycare. After reading the descriptions of the two fictitious studies, the couples were asked to rate the design of the studies, list the strengths and weaknesses of each study, and indicate which one they found to be more convincing. Not surprisingly, conflicted couples rated the fictitious study in favor of daycare more positively, whereas non-conflicted couples evaluated the fictitious study in favor of home care more 
positively. In post-experimental evaluations of daycare and home care, couples who were initially conflicted about their decision of whether to send their future child to daycare or not were subsequently less conflicted about their decision, thus showing a change in their attitudes, presumably based on the biased assimilation of information from the article that supported the use of day care; unconflicted couples on the other hand only showed a marginal change in their attitudes towards daycare, likely because they were less motivated to do so. These results led Bastardi et al. (2011) to conclude that their study lends support to the notion that evaluations of scientific evidence can be influenced by what one desires to be true, and not just what one already believes to be true.

In the experiments conducted by Lord et al. (1979) and Bastardi et al. (2011), the topics used for evaluation were presumably of high importance to the participants that evaluated the fictitious studies that were used. However, Anderson et al. (1980) and Masnick and Zimmerman (2009) have both shown that it is not just topics for which people already have strong biases, desires, or long held beliefs about that they may evaluate in a biased manner. In Anderson et al. (1980), the researchers sought to find whether participants would continue to support a theory about a topic they likely had not previously contemplated, even if the minimal evidence they were given for the theory was discredited; they also looked at whether making people provide their own explanations for the relation between the two variables being examined by a study claiming to lend support to the theory would increase their tendency to hold on to the theory after it was discredited.

The topic in Anderson et al. (1980) was whether a proclivity for risk-taking behavior would positively or negatively affect the job performance of firefighters. 
Participants in the experimental condition of this study were provided with weak information leading to one of the two possible conclusions. Next they were asked to generate a written explanation for why the relationship they were told about might exist. Afterwards, some of the participants in the experimental condition were falsely debriefed whereas others were not. During this false debriefing session, they were told that the information they had initially been given was false. Finally, with the control group, they were asked to fill out measures assessing their beliefs concerning the two variables and the predictive power of the relationship.

What was found was that when subjects were provided with weak data, and not debriefed, the weak data had a strong effect on their theories about the relationship between risk-taking behavior and job performance by firefighters; Anderson et al. (1980) also found that even when the participants were debriefed, the debriefing had little influence on their beliefs about the relationship between the two variables. In fact, even when there was a total refutation of the evidence upon which their belief was based, there was still a strong relationship between the initial information and the subsequent belief. This finding indicates that the participants failed to make revisions to their beliefs, even in light of this new information, raising questions about the tenacity of beliefs in the real world, given that such a complete discrediting of evidence rarely happens in the real world (Anderson et al., 1980).

In a subsequent experiment Anderson et al. (1980) presented participants with case studies highlighting a successful and an unsuccessful firefighter. Some were then asked to write an explanation for the success or lack of success of the firefighters, while others were not. Some from both groups were put through a false debriefing. All 
participants completed assessments of their beliefs on the topic. Again, what was found was that exposure to the case studies had a powerful effect on later beliefs. It was shown that these effects persisted even after the false debriefing in both those who were asked to generate an explanation as well as in those who were not, although the relationship was weaker for those who were not asked to generate an explanation. In this study, the researchers concluded that people maintain beliefs with more tenacity than would be expected even if the maintenance of their beliefs is not logically warranted, that one's initial beliefs on a topic may continue even when the evidence upon which they are based is invalidated, and that the generation of causal explanations by an individual for a relationship may strengthen the tenacity of such beliefs.

In a similar line of research, Masnick and Zimmerman (2009) also looked at how people process information on a topic that is less politicized, and presumably one that people have less ingrained or solidified opinions about compared to those typically used in this line of research. In their study the topic was whether direct instruction was a better method of instruction in early science education compared to discovery learning. They gave their subjects brief descriptions of the issue. The subjects were then asked to indicate which method of instruction they believed was more effective. They all then read the same study and were asked to evaluate the study in terms of its methodological design and the appropriateness of the sample. Afterwards, they were given one of four reports with the findings either favoring direct instruction or discovery learning, and either containing an explanation or not containing an explanation. When they were done reading the conclusion they were given, participants were asked to rate the conclusion based on obviousness, importance, and interestingness; they were also asked to evaluate 
the study for the appropriateness of the experimental design, measures, and the sample used.

What Masnick and Zimmerman (2009) found was that when the initial beliefs of participants were confirmed, they rated the methods of the experiment more positively; when the participants' initial beliefs were disconfirmed, they rated the methods of the experiment more negatively. They also rated the study as more obvious and important when their initial beliefs were confirmed. The ratings of obviousness for the conclusion of the study were unaffected by the presence of an explanation or lack of an explanation.

Overall, it appears that beliefs and opinions can quickly form and be based on minimal or vague information. Subsequently, once they do, they become quite resilient to disconfirming information, even in the face of complete invalidation. Intuitively, one can imagine why this might be the case for important topics such as those related to serious medical issues, contentious political debates, or the early developmental environment of one's child, but it also appears to be the case with less important topics many people have never thought about, such as what qualities make a good firefighter or whether one method of science instruction is better than another. Yet, still, questions remain concerning what cognitive or neurological processes underlie these patterns.

One prominent hypothesis for why so many people have such difficulty in objectively assessing new information concerning their beliefs is that there are unconscious ego-protective processes in place that help people maintain a sense of self and reality, enhance self-esteem, and enhance their opinions of the groups to which they belong, such as those pertaining to religion or social class (Klaczynski \& Narasimham, 1998; Klaczynski \& Robinson, 2000). In fact, it has been shown that when beliefs are 
threatened through disconfirming evidence, people will report higher levels of emotional arousal, as measured by the Multiple Affect Adjective Checklist, which assesses depression, anxiety, and hostility (Russell \& Jones, 1980). A prominent example of this is outlined in Festinger (1956) in which an end-of-the-world cult survived the date of their predicted apocalypse and subsequently faced the ensuing cognitive dissonance. Several cult members refused to accept the disconfirmation and re-interpreted the event as a confirmation of their previously held beliefs.

A related hypothesis concerning the underlying mechanisms of motivated reasoning that has been supported through fMRI studies is that when an individual encounters evidence that may lead them to an emotionally aversive conclusion, such as a political figure they respect being caught in a lie, areas of the brain associated with pain, punishment, and negative affect (e.g., the insula and orbitofrontal cortex) exhibit greater activation, whereas the reestablishment of prior beliefs through rationalization or the presentation of redeeming information, such as an exonerating explanation for the misunderstanding their respected political figure was involved in, is associated with the activation of areas associated with reward (e.g., the ventral striatum and caudate nucleus). According to such biological accounts, motivated reasoning is mediated by areas of the brain involved in response conflict, implicit appraisal of emotionally threatening information, and social and moral evaluation (e.g., the anterior cingulate cortex, the ventral medial prefrontal cortex, and the posterior cingulate cortex; Harris et al., 2007; Harris et al., 2009; Westen et al., 2006). 


\section{Memory}

A topic related to motivated reasoning is how various factors that have typically been found to influence people's analysis and interpretation of new information such as belief-congruence, perceived importance, personal motivation, and superficial information affect memory. A number of social factors have been shown to have an effect on memory including social-cognitive, social-motivational, interpersonal, and group and collective influences (Blank, 2009). Among the social cognitive influences Blank (2009) describes are social-cognitive representations such as traits and stereotypes that are remembered for behaviors, self-concept, and whether information is congruent or incongruent with current attitudes. With regard to this last social-cognitive influence on memory, there are questions concerning whether the congruence of new information with current attitudes, beliefs, or opinions will influence how well it is remembered, or whether certain aspects of it will be remembered better or differently than others.

Previous research has indicated that such factors indeed highly influence memory on a range of topics including politics, sports, and pseudoscientific beliefs pertaining to the paranormal, both in the lab and in real life (Hastorf \& Cantril, 1954; Jones \& Russell, 1980; Levine \& Murphy 1943; Wiseman \& Morris, 1995). Using small samples of carefully selected students known for their reputations for either supporting or opposing Communism, Levine and Murphy (1943) found the belief congruence of learned information could correlate with that information being learned better and forgotten more slowly.

Following a football game between Princeton and Dartmouth that was plagued by controversy due to numerous penalties and a couple of well publicized injuries, 
researchers from both institutions surveyed students from both schools to gauge opinion about the game, and showed samples from both populations a movie of the game, asking them to note violations of the game's rules and the severity of the violations. Although both samples had similar levels of knowledge of and experience with football, perceptions and memories of the game varied greatly between schools. Princeton students overwhelmingly judged the game to be "rough and dirty," as opposed to "clean and fair," largely believed that Dartmouth initiated the rough play, thought Dartmouth violated the rules of the game twice as much as Princeton, and thought that Dartmouth's infractions were more severe than Princeton's (Hastorf \& Cantril, 1954, pp 130). Dartmouth students also largely saw the game as "rough and dirty," but were more likely to see both sides as responsible for instigating the rough play, and saw both teams as violating the rules of the game with equal frequency. These divergent interpretations and memories of the same event led the researchers to conclude that people attend to, perceive, and remember events not as they are but through a lens of personal relevance.

In an experiment in which participants that were either believers in or skeptics of the paranormal were asked to read fabricated journal articles proving or disproving the existence of ESP, believers were found to exhibit decreased recall for fabricated articles that disproved ESP, whereas believers and skeptics demonstrated similar levels of recall for those that proved ESP (Russell \& Jones, 1980). Comparable patterns are also often demonstrated in experiments in which participants are asked to view alleged psychic demonstrations. When Jones and Russell (1980) had both believers and skeptics view a pseudopsychic demonstration involving ESP cards with either a $60 \%$ or $20 \%$ hit rate, with $20 \%$ being what would be expected through chance alone, both believers and 
skeptics who witnessed the successful demonstration were more likely to report that they had witnessed a demonstration of psychic ability. However, when the pseudopsychic demonstration exhibited a hit rate at chance levels, believers, but not skeptics, still reported having witnessed a successful demonstration of psychic ability.

In similar experiments, Wiseman and Morris (1995) played videos of alleged psychic demonstrations by a magician for both believers and skeptics, then asked them a series of recall questions dealing with information that was either relevant or irrelevant to how the tricks were performed; these demonstrations involved ESP cards and bending cutlery by gently rubbing a given utensil. Unlike in Jones and Russell (1980), in Wiseman and Morris (1995)'s experiments, believers generally rated the demonstrations as more paranormal than skeptics despite the success of the alleged psychics, although this difference was not always significant. When recall questions on either relevant or irrelevant information indicating trickery were administered, skeptics tended to recall more relevant information than believers. However, if participants were informed that they had witnessed magic tricks immediately after the first recall task, as opposed to five minutes later, then asked to perform a second recall task, both believers and skeptics recalled relevant information at a similar level.

Furthermore, in direct investigations of memory intrusions, or false memories, concerning not just relatively recent events such as a football game or a pseudopsychic demonstration one has just viewed, but events dating back years or decades, prior beliefs and opinions have been shown to once more play a role. Often researchers study memory intrusions using impersonal word lists in a lab setting (Leding, 2011). However, it is not uncommon for researchers to also attempt to create false memories in people for more 
meaningful, or at least more personal, events through a number of more complex, potentially more ecologically valid methods (Berkowitz et al., 2008; Bernstein \& Loftus, 2009; Desjardins \& Scorbia, 2007; Frenda, Knowles, Saletan, \& Loftus, 2013; Sacchi, Agnoli, \& Loftus, 2007; Strange, Hayne, \& Garry, 2008; Wade, Garry, Read, \& Lindsay, 2002).

Falsified reports from the parents of participants containing self-relevant information about participants have been used to create at least partial false memories concerning a prank participants allegedly played on a teacher as a child (Desjardins \& Scoboria, 2007). News clippings describing fictitious accounts of a costumed Disney theme park employee behaving appropriately or inappropriately around children have been used to increase the confidence people reported in having been appropriately or inappropriately licked by "Pluto" while visiting a Disney theme park as a child (Berkowitz et al., 2008). The fabricated analyses of personality exams and food history questionnaires have been used to alter food preferences within certain limits by convincing people they had negative experiences with certain foods as children (Bernstein \& Loftus, 2009). Also, much has been done in recent years to create false memories for both personal experiences and major political events through the digital manipulation of both family photographs and images relating to historical events and political figures (Frenda, Knowles, Saletan, \& Loftus, 2013; Sacchi, Agnoli, \& Loftus, 2007; Strange, Hayne, \& Garry, 2008; Wade, Garry, Read, \& Lindsay, 2002).

One of the more well-known examples of using doctored photographs to induce false memories involves taking an image of a person as a young child from a photograph depicting an actual event and inserting that image of the person into a hot air balloon 
depicted in a separate photograph, possibly with a parent, as a means to stimulate the creation of false memories. When presented in conjunction with the proper interview techniques this specific manipulation to photographs can yield false memories in roughly 50 percent of participants, both in their late teens or twenties (Wade et al., 2002), and in older children around the age of 10 (Strange et al., 2008).

With regard to creating false memories for events within historical or political contexts through the digital manipulation of images, Sacchi et al. (2007) were able to digitally alter an iconic image from Time magazine of a single student standing in front of a line of tanks to make people remember larger crowds of protesters at that event, as well as a photo of a well-known, peaceful, anti-war protest in Italy to make Italian participants remember it as more violent. Also, Frenda et al. (2013) demonstrated that not only could they use digitally altered photos involving famous American political figures to create or alter memories for recent significant events in American politics, such as George Bush hanging out with Roger Clemens at his Texas ranch while New Orleans was still in a state of emergency following Hurricane Katrina or President Obama shaking hands with Iranian President Mahmoud Ahmadinejad, but that people tended to remember these kinds of false events more frequently when they were congruent with their current political beliefs. One hypothesis put forth by Frenda et al. (2013) for why beliefcongruence in terms of political ideology may influence the acceptance of doctored images, and the subsequent occurrence of false memories in this way, was that it is easier for people to accept new information concerning a person they dislike doing something they disapprove of than a person they dislike doing something they approve of or a person they like doing something they disapprove of, hence leading to a greater degree of 
perceived realism and imaginability for the occurrence. These findings are generally consistent with and seem to potentially be an extension of the general pattern found in motivated reasoning research that belief-congruence influence how people interpret new information (Boysen \& Vogel, 2007; Boysen \& Vogel, 2008; Corner et al ., 2012; Jones \& Russell, 1980; Levine \& Robinson, 1943; Lord, et al., 1984; Lordet al., 1979; Munro et al., 2004; Plous, 1991), and can potentially be explained by notions that there may be something not only emotionally, but also physiologically aversive about learning of a favored political figure's questionable actions (Westen et al., 2006).

\section{Theoretical Explanations}

Two frameworks often used to interpret both motivated reasoning and memory research are dual processing theory and fuzzy-trace theory. Although there are many versions of dual processing theory including Sloman (1996)'s associative and rule-based form and a version by Epstein (1994) which attempts to establish an all-encompassing framework for practically all psychological phenomena, according to the most basic form, the mind processes information through two processes or systems. One is automatic, quick, effortless, and used as a default. The other is effortful, requires focus and attention, and comes less naturally (Kahneman, 2011). The former is heuristic whereas the latter is analytic. According to dual process theory, it is predicted that beliefcongruent information will be processed analytically, and thus processed more deeply, resulting in better memory for such information, whereas belief-incongruent information will be processed heuristically, and thus not processed as deeply, resulting in poorer recall for the information. Dual process theories would also predict that some forms of 
seductive details, such as superficial neurocognitive information, will be processed heuristically, and repeated testing will compel individuals to process information more analytically or deeply, thus resulting in better memory for that information; the assumption here is that when new information is processed more deeply, it results in greater cognitive activity relating to the information, which results in better memory for the information.

Contrarily, there are other researchers who have studied memory for beliefcongruent and belief-incongruent information from a dual process perspective who would put forth more nuanced hypotheses concerning the relationship between these variables. For example Klaczynski and Robinson (2000) have postulated that unless individuals are analytically oriented, they tend to process belief-congruent information heuristically, attempting to assimilate the new information into their beliefs in an attempt to preserve their theory, using stereotypes, memories, and intuition, whereas they process beliefincongruent information analytically, attempting to reject the new information through various strategies that tend to be associated with scientific reasoning. Additionally, Blank (2009) also suggests that memories and beliefs that form through heuristically processed information are less stable than those processed analytically. Hence, it would follow that new belief-congruent information would not be remembered as well as new beliefincongruent information. It would also be argued that information that is belief-congruent would be more open to distortions or intrusions because it is being processed heuristically, and that therefore new information that is belief-incongruent and processed analytically would be remembered better, or at least be open to fewer distortions (Blank, 2009). 
Fuzzy-trace theory, like dual process theory, is also a broad attempt to explain several major cognitive processes. In a basic form, fuzzy-trace theory, as described by Titcomb and Reyna (1995), suggests that when new information is encoded, two memory traces are formed. One is a verbatim trace, which, although not quite an exact cognitive replica of all the information that could have been potentially encoded from a stimulus or the environment, is still proposed to be detail oriented. The other is a gist trace, which represents a more general representation or summary of stimuli or events. Verbatim traces are believed to be forgotten relatively quickly, although not completely. Gist traces are believed to be forgotten more slowly. With regard to memory intrusions, it is believed that they are more likely to occur when they are consistent with current knowledge structures or gist given that in such cases the misleading information is not necessarily incongruent with one's current beliefs or memories, or when new misleading information is presented close to the time of recall given that in such instances the misleading information would be competing with more accurate information at the time of recall. 


\section{CHAPTER II \\ STUDY OVERVIEW}

In the current study, several of the issues discussed above were examined more closely. Specifically, an attempt was made to examine the role of belief-congruence in memory, as well as the effect of superficial scientific information and repeated testing. Specifically, the questions examined were as follows. (1) Is belief-congruent information remembered better or worse than belief-incongruent information? (2) Does the addition of superficial scientific information to belief-congruent or belief-incongruent information influence how well the newly presented information is remembered? (3) Does repeated testing have an effect on memory for the information? (4) Do any of these factors elicit a greater number of memory intrusions in a free recall task?

These questions were examined using brief, fabricated, press release-style texts that took a position, either for or against, a controversial topic, and were either accompanied or not accompanied by superficial scientific information. The presentation of these texts was followed by two free recall tasks. One occurred immediately after the presentation of the text. The other occurred one week later. The use of fabricated texts, superficial information, and retesting are common in research on motivated reasoning (Anderson et al., 1980; Bastardi, et al., 2011; Corner et al., 2012; Lord et al., 1979; Masnick \& Zimmerman, 2009; Weisberg et al., 2008), seductive details (Harp \& Mayer, 1998; Mayer et al., 2008; Rowland et al., 2008; Weisberg et al., 2008), and memory 
(Leding, 2011; Levine \& Murphy, 1943; Roediger \& Karpicke, 2006; Wiseman \& Morris, 1995).

The controversial topic used in this study was paranormal phenomena. The brief, fabricated, texts described recent comprehensive reviews of hundreds of articles that examined claims of the paranormal scientifically. There were four versions of the text. Two supported claims of the paranormal and subsequently encouraged further scientific investigation of paranormal topics; two did not support claims of the paranormal and subsequently discouraged further scientific investigation of paranormal topics. One of each type of article contained superficial scientific information, specifically, superficial neurocognitive information. With regard to the free recall tests, as mentioned previously, one was presented to participants right after reading one of the four texts; the other was presented one week later.

The four texts were modeled upon those found in Zeigler, Walker, and Ackett (2002), and informed by descriptions of rationales for paranormal beliefs and purported bodies of evidence for paranormal phenomena found in Shermer (2011). Accuracy of recall was evaluated using idea unit standards as described by Dunlosky, Hartwig, Rawson, and Lipko (2010), as well as previously used by Roediger and Karpicke (2006). The superficial scientific information used was neurocognitive in nature due to the previously demonstrated ability of such information to elicit higher ratings for poor explanations in fabricated scientific reports (Weisberg et al., 2008). The rationale behind having participants perform a recall task on more than one occasion was that it has previously been found that belief-incongruent information is forgotten more quickly (Levine \& Murphy, 1943). Also, it has been hypothesized that information deemed 
unimportant, either consciously or unconsciously, decays more quickly (Wiseman \& Morris, 1995), and it has been shown that repeated testing can enhance retention (Roediger \& Karpicke, 2006), as well as false recall (Leding, 2011). It should be noted, however, that the false recall demonstrated by Leding (2011) was only shown in individuals who scored higher on a measure of need for cognition, a measure of one's disposition towards effortful, elaborate information processing. For this reason participants also filled out the Rational-Experiential Inventory (REI), which is designed to measure tendencies towards rational and experiential thinking styles, and said to improve upon older forms of similar scales by better balancing the number of questions for each scale, as well as the positive vs. negative wording of scale items (Pacini \& Epstein, 1999).

With regard to the chosen controversial topic, it was a topic that presumably most undergraduate participants had some familiarity with. Also, belief in the paranormal can easily be measured using the Revised Paranormal Belief Scale (R-PBS), which has been shown to demonstrate validity and reliability in assessing such beliefs (Tobacyk, 2004).

The hypotheses for the current study were as follows: (1) Given that the motivated reasoning literature tends to show that the congruence of new information with one's beliefs, biases, and desires can cause an individual to rate the information more positively, or as more obvious, more valid, or more methodologically sound, it was hypothesized that such information would also be remembered better, and that beliefcongruence would lead to greater recall; this would also be consistent with prior findings (Levine \& Murphy, 1943; Wiseman \& Morris, 1995). (2) Given that previous studies have found that the presence of seductive details result in poorer memory for information 
not related to the added seductive details (Harp \& Mayer, 1998) it was hypothesized that the presence of superficial scientific information would decrease recall. (3) As for the effects of repeated testing, it was predicted that retention would improve with repeated testing, especially for belief congruent information. (4a) It was also predicted that there would be increased memory intrusions for those with greater levels of paranormal belief when exposed to belief-incongruent information, and (4b) that there would also be increased memory intrusions for individuals with a tendency towards more rational styles of thinking (e.g., need for cognition) on later tests. These predictions concerning repeated testing and memory intrusions were informed by the work of Leding (2011), Levine and Murphy (1943), Pacini and Epstein (1999), Roediger and Karpicke (2006), Russell and Jones (1980), and Wiseman and Morris (1995). 


\section{CHAPTER III}

\section{METHODS}

\section{Participants}

Initial power calculations indicated that with a medium effect size ( $f=0.25)$, with alpha set at 0.05 and power at 0.8 for ANOVA the sample size needed $=184$. Data were collected for 249 individuals (46 male; 198 female; 5 sex not reported). Participants' mean age was 19.38 years old $(S D=1.88)$. The ethnic composition of the sample was as follows: $72.4 \%$ white-non-Hispanic, $10.8 \%$ black-non-Hispanic, 7.6\% Hispanic, $3.6 \%$ Asian/Pacific Islander, 3.2\% other, 2.4\% not reporting.

Data from nine participants needed to be excluded from all analyses due to their failure to properly fill out one or more of the surveys provided to them. Data from an additional 32 participants needed to be excluded from all analyses due to their failure to properly read through all the materials provided to them as indicated by either explicitly writing that they did not read or see the materials on the first memory test or leaving the first memory test blank. Also, data from another 35 participants were excluded from analyses involving data collected at the time two testing session due to their failure to show up for the time two testing session.

Participants were Illinois State University undergraduate students who were at least 18 years old. They were recruited using an electronic enrollment system that required students to sign up for both testing sessions and later sent notifications to 
students via email prior to scheduled participation dates. In exchange for 60 minutes of participation over the course of two 30 minute sessions they were compensated withcourse credit or extra credit for a psychology course they were enrolled in at the time of participation.

\section{Revised Paranormal Belief Scale (R-PBS)}

The R-PBS (Appendix A), as described in Tobacyk (2004) is a measure of paranormal belief that has demonstrated both validity and reliability (Test-retest reliability for the full scale: $\alpha=.92$ according to Tobacyk, 2004). It is an update of an instrument developed by Tobacyk and Milford (1983), which was intended to evaluate belief in several different types of phenomena that are considered incompatible with science unless one or more basic scientific principles would be revised, and to base these divisions between different types of phenomena in correlations of beliefs as opposed to untested assumptions. Seven subscales are present; these include subscales for traditional religious belief, psi, witchcraft, superstition, spiritualism, extraordinary life forms, and precognition. Items (e.g., "The soul continues to exist though the body may die") are addressed using a seven point scale (1= Strongly Disagree, $7=$ Strongly Agree $)$.

\section{Rational-Experiential Inventory (REI)}

The Rational-Experiential Inventory (REI; Appendix B) is designed to measure tendencies towards rational and experiential thinking styles, and said to improve upon older forms of similar scales by better balancing the number of questions for each scale, as well as the positive vs. negative wording of scale items. Validity and reliability 
(Rationality scale, $\alpha=.90$; Experientiality scale, $\alpha=.87$ ) have also been demonstrated. Subscales for experiential engagement, experiential ability, rational engagement, and rational ability are present. Items (e.g., "I don't reason well under pressure") are addressed on a scale of one to five with one meaning "definitely not true of myself" and five meaning "definitely true of myself" (Pacini \& Epstein, 1999).

\section{Texts and Scoring}

The four texts (Appendixes C-F), for or against paranormal phenomena, with or without superficial neurocognitive information, as discussed previously, were modeled upon those found in Zeigler et al. (2002), informed by descriptions of rationales for paranormal beliefs and purported bodies of evidence for paranormal phenomena found in Shermer (2011), and scored using idea unit standards as described by Dunlosky et al. (2010), and used by Roediger and Karpicke (2006), as well as Dunlosky et al., (2010); additional instructions were provided by Dunlosky (personal communication).

In essence, an idea unit is an intermediate conceptual unit of information that falls between an atomic proposition, which is the smallest unit of information that still retains some level of truth value, and a complex proposition, which has been described as multiple atomic propositions contained within a single sentence (Dunlosky et al., 2010). Idea units for these materials were created by two individuals who divided the texts into idea units independently of one another before later comparing their divisions and negotiating the final divisions. Scoring was carried out by two blind raters. Their average intraclass correlation coefficient for time one recall was $r=.86$ and $r=.827$ for time two 
recall. Intrusions were scored in a similar manner using the same two blind raters, although the intraclass coefficient for time one intrusions was only $r=.529$.

\section{Procedure}

Participants were tested in groups of up to 20. Informed consent was given by participants after they read and signed an informed consent document. Participants were informed that they would receive two packets. They were told that the first would contain a demographics form, two assessments, and an article, but were not informed of the contents of the second packet; with regard to the second packet, they were only notified that they would receive it upon finishing with the first packet. Also, they were not informed of the true nature of the study, the contents of the assessments or article, or that the second packet would contain questions concerning the article that they were to read. The reason for this was to recreate as best as possible a realistic scenario in which they casually read a news article or blog post, and are then asked by a friend or colleague what they had just read about and what they had read about one week later. After going through this procedural overview with the researcher, participants were then given the first packet.

Upon receiving the first packet, participants completed the demographic form, then two questionnaires. The first, the R-PBS, evaluated their belief in various paranormal phenomena using a seven-point scale for each question. The second, the REI, evaluated their tendencies towards rational and experiential thinking styles using a fivepoint scale for each question. 
After filling out the R-PBS and the REI, participants read one of four versions of a brief, fabricated, press release-style text. Two versions supported the existence of paranormal phenomena; two versions did not. One of each version used superficial neurocognitive information and one of each version did not use superficial neurocognitive information.

Participants were randomly assigned to one of the four versions of the article. Subsequently, some participants received an article that was congruent with their beliefs, regardless of whether they believed in the paranormal or not, and some received an article that did not agree with their current beliefs. Afterwards, they answered a question concerning how persuasive they found the article they read.

Participants then had their materials collected and were given a free recall test in which they were asked to recall as much information from their brief, fabricated, press release-style text as they could. Afterwards, they were free to leave, but were asked to return one week later to complete the same free recall task again. Participants were aware of the second session upon initially signing up for the experiment but, again, were not informed of what they would be doing during this second session until they arrived. These recall procedures were similar to those previously implemented by Dunlosky et al. (2011) and Roediger and Karpicke (2006). Upon completing the second free recall task, participants were debriefed and given a second consent form. Those that did not return for the second session were sent an email at the end of the semester with an attached copy of the debriefing statement and a notification that if they did not request to have their data from the first testing session excluded from the study via email, their data would be used 
in future analyses. All materials and procedures were reviewed and approved by Illinois State University's institutional review board. 


\section{CHAPTER IV \\ STATISTICAL ANALYSES}

Initially, a 2 (article stance: pro or con ) $\times 2$ (belief-congruence: congruent or incongruent $) \times 2$ (seductive details: present or absent $) \times 2$ (test: immediate and after one week) mixed ANOVA was going to be performed to determine if belief-congruence, seductive details, or test timing had an effect on free recall for new information concerning the paranormal. Article stance, belief-congruence, and the presence of seductive details were going to be analyzed as between-participant variables and test time was going to be analyzed as a within-participant variable. The variable of beliefcongruence was going to be derived by taking the median of total R-PBS scores to perform a median split, relegating individuals below the median to a "skeptic" category and individuals above the median to a "believer" category, and then dividing them into categories of "belief-congruent" and "belief-incongruent" based on whether the article they received was congruent with their beliefs. Creating such quasi-independent variables through the median split of a continuous variable has been done repeatedly in the past by researchers examining the influence of paranormal belief on measures of attention, perception, and memory (Jones \& Russell, 1980; Russell \& Jones, 1980; Wiseman \& Morris, 1995), and similar procedures are also common within motivated reasoning research wherein participants are often divided into "pro," "con," or "neutral" categories based on their responses a single Likert question (Boysen \& Vogel, 2007; Munro 2010) 
or their additive score on a larger multi-item scale (Corner et al., 2012). However, because the data collected for total R-PBS score was normally distributed (see Figure 1), using a median split to generate the categories of "believer" and "skeptic" or "congruent" and "incongruent" could not be justified.

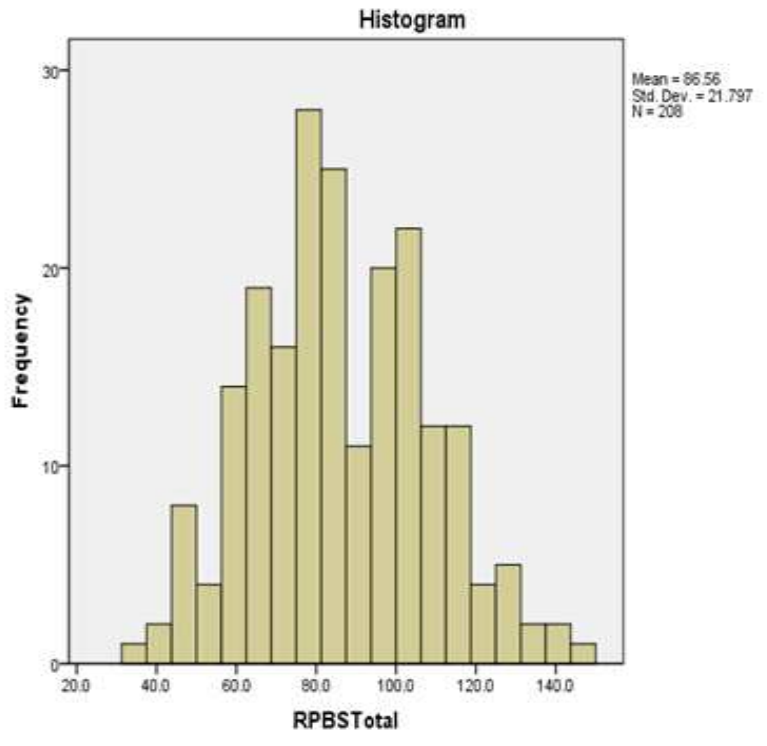

\section{Figure 1: Distribution of R-PBS Total}

Therefore a 2 (article stance: pro vs. con) $\times 2$ (seductive details: present or absent) $\times 2$ (test: immediate and after one week) mixed ANCOVA, with total R-PBS as a continuous predictor variable, was performed instead to determine if paranormal belief, seductive details, or test timing have an effect on free recall for new information concerning the paranormal. Article stance and the presence of seductive details were analyzed as between-participants factors. Test time was analyzed as a repeated measures factor. Total R-PBS score was analyzed as a continuous predictor variable as a means to have it included in the ANOVA; given that R-PBS score was not influenced by valence $F(1,207)=.735, p=.392, \eta_{p}{ }^{2}=.004$, or seductive details $F(1,207)=.079, p=.779, \eta_{p}{ }^{2}$ $=.000$ analyzing it in this way was deemed reasonable. 
An additional 2 (article stance: pro vs. con) $\times 2$ (intrusions: time 1 and time 2 ) mixed ANCOVA, with total R-PBS as a continuous predictor variable, was performed to determine if paranormal belief or test timing have an effect on memory intrusions when recalling new information concerning the paranormal. Article stance was analyzed as a between-participants factor. Test timing was analyzed as a repeated measures factor. Regression analyses were performed to examine the effects of the REI rationality scale on intrusions.

Due to a large number of participants that failed to show up to the second testing session, 2 (article stance: pro vs. con) $\times 2$ (seductive details: present or absent) ANCOVAs were also performed to examine the effects of paranormal belief and seductive details on memory for new information concerning the paranormal and memory intrusions when recalling new information concerning the paranormal at time one alone. Once more, total R-PBS was included as a continuous predictor variable. 


\section{CHAPTER V}

\section{RESULTS}

The first hypothesis was that belief-congruent information would lead to higher levels of recall than belief-incongruent information. As mentioned previously, because data for total R-PBS scores were normally distributed, participants could not be divided into "believers" and "skeptics" using a median split, and therefore the influence of beliefcongruence could not be examined. However, the influence of paranormal belief was examined, although it had no significant effect on recall, $F(1,206)=.271, p=.604, \eta_{p}{ }^{2}=$ .002 (see Figure 2). For means and standard deviations, see Table 1. 
Table 1: Descriptive Statistics for Time 1 Recall

\begin{tabular}{|c|c|c|c|c|}
\hline Valence & Seductive Details & $M$ & $S D$ & $N$ \\
\hline \multirow[t]{3}{*}{ Negative } & $\begin{array}{l}\text { No Seductive } \\
\text { Details }\end{array}$ & 4.44 & 2.84 & 48 \\
\hline & Seductive Details & 3.47 & 2.22 & 59 \\
\hline & Total & 3.91 & 2.55 & 107 \\
\hline \multirow[t]{3}{*}{ Positive } & $\begin{array}{l}\text { No Seductive } \\
\text { Details }\end{array}$ & 5.35 & 3.57 & 54 \\
\hline & Seductive Details & 4.39 & 3.32 & 46 \\
\hline & Total & 4.91 & 3.48 & 100 \\
\hline \multirow[t]{3}{*}{ Total } & $\begin{array}{l}\text { No Seductive } \\
\text { Details }\end{array}$ & 4.92 & 3.26 & 102 \\
\hline & Seductive Details & 3.88 & 2.78 & 105 \\
\hline & Total & 4.39 & 3.07 & 207 \\
\hline
\end{tabular}

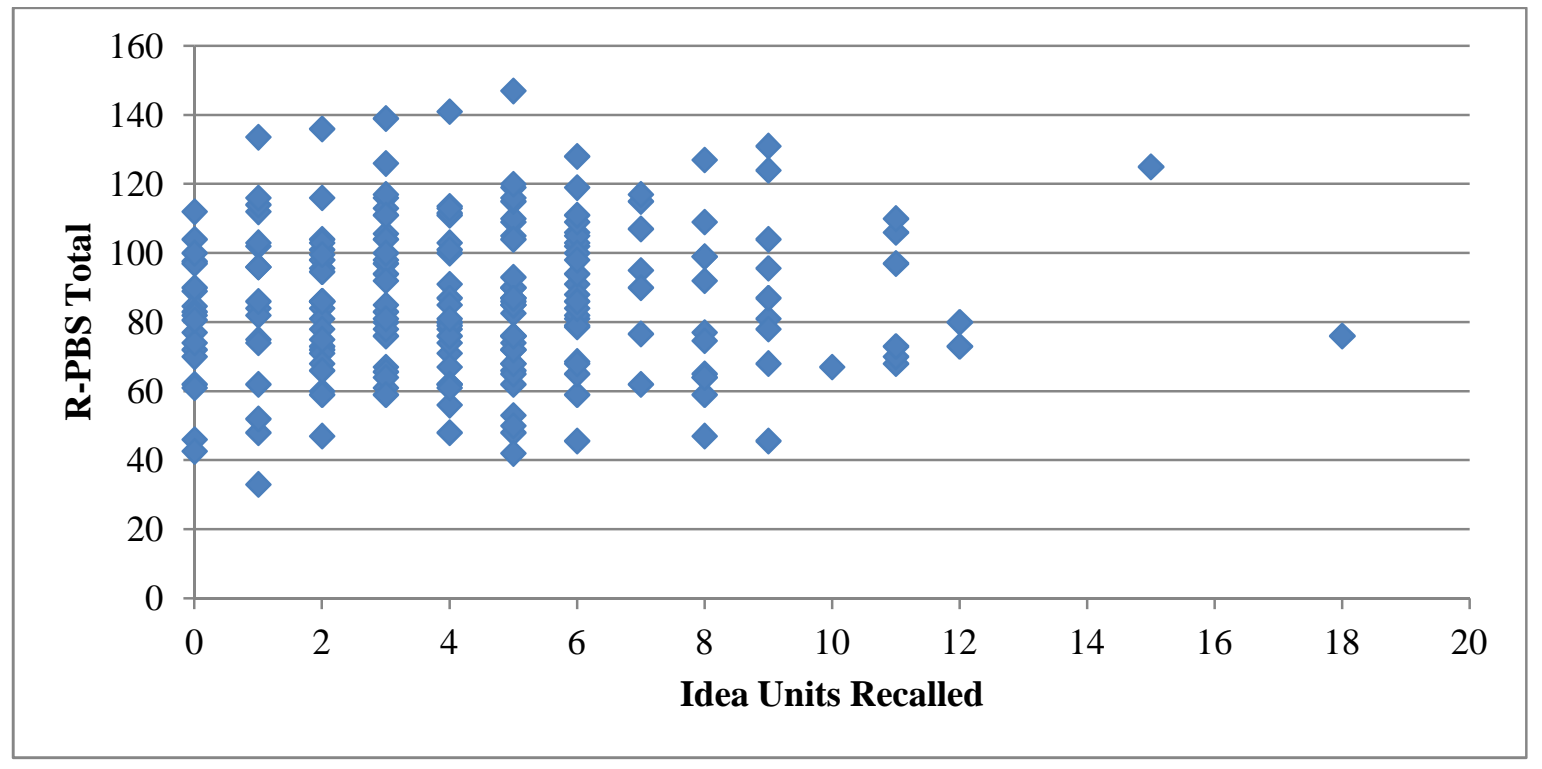

Figure 2: Influence of Paranormal Belief on Time 1 Recall

The second hypothesis was that the presence of seductive details would lead to poorer recall for new information concerning the paranormal, regardless of level of belief or article valence. This was demonstrated at the immediate free recall testing session $F(1$, 
$207)=5.268, p=.023, \eta_{p}{ }^{2}=.025$ (see Figure 3 ). Additionally, a marginal withinparticipants interaction was observed between the presence of seductive details and time of testing, $F(1,173)=3.462, p=.065, \eta_{p}{ }^{2}=.02($ see Figure 4$)$, revealing that although participants that did not encounter seductive details in their article remembered more when tested immediately after reading their article compared to those who did encounter seductive details, participants in both conditions remembered equally little when tested one week later. For means and standard deviations see Tables 1 and 2.

Table 2: Descriptive Statistics for Recall, Time 1 and 2

\begin{tabular}{lllrrr}
\hline & Seductive Details & Valence & $M$ & $S D$ & $n$ \\
\hline Recall Time 1 & \multirow{2}{*}{ No Seductive Details } & Negative & 4.52 & 2.93 & 44 \\
& & Positive & 5.41 & 3.69 & 44 \\
& \multirow{4}{*}{ Seductive Details } & Total & 4.97 & 3.34 & 88 \\
& & Negative & 3.85 & 2.17 & 47 \\
& \multirow{2}{*}{ Total } & Positive & 4.47 & 3.51 & 38 \\
& & Total & 4.13 & 2.84 & 85 \\
& & Negative & 4.18 & 2.57 & 91 \\
& No Seductive Details & Pegitive & 4.98 & 3.61 & 82 \\
& & Total & 4.55 & 3.13 & 173 \\
\hline \multirow{2}{*}{ Recall Time 2} & Positive & 2.39 & 2.65 & 44 \\
& \multirow{2}{*}{ Seductive Details } & Total & 2.26 & 2.37 & 88 \\
& & Negative & 1.91 & 2.05 & 47 \\
& & Positive & 2.42 & 1.64 & 38 \\
& Total & Total & 2.14 & 1.88 & 85 \\
\hline & Negative & 2.02 & 2.06 & 91 \\
& & Positive & 2.40 & 2.23 & 82 \\
& & Total & 2.20 & 2.14 & 173 \\
\hline
\end{tabular}




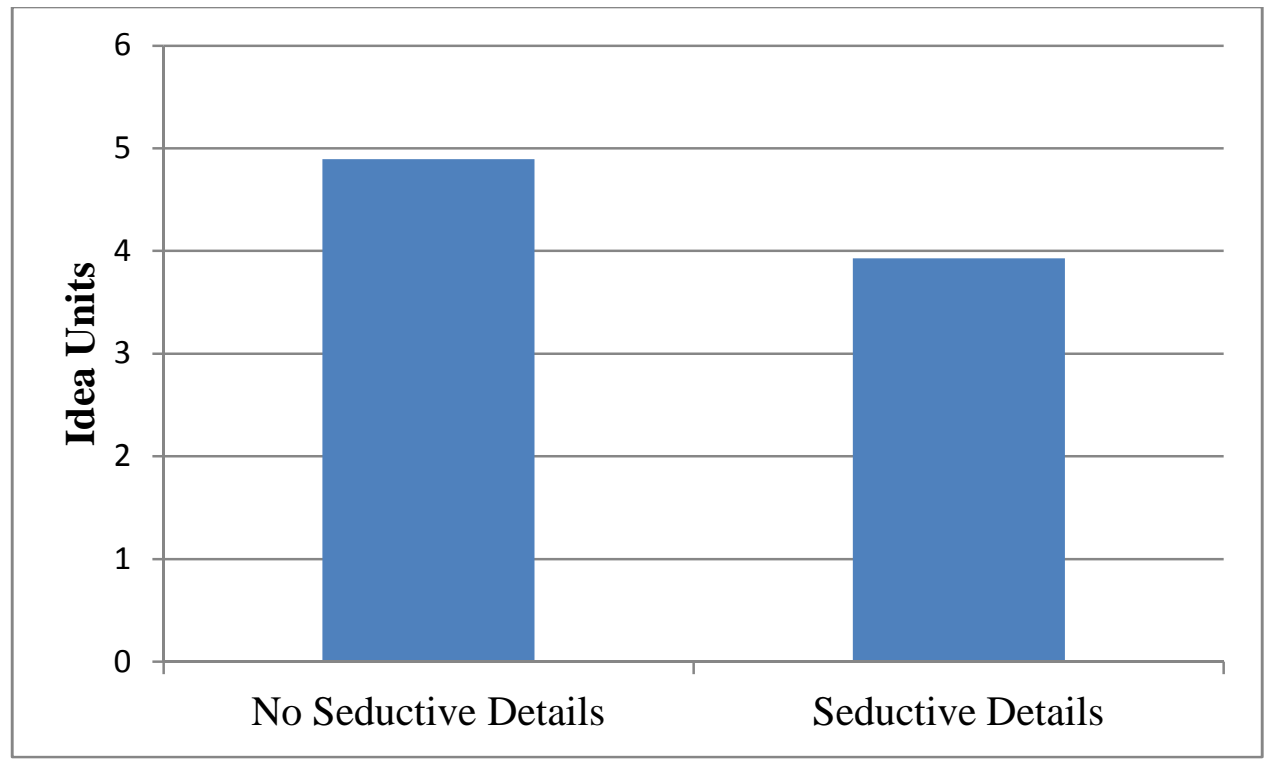

Figure 3: Influence of Seductive Details on Time 1 Recall

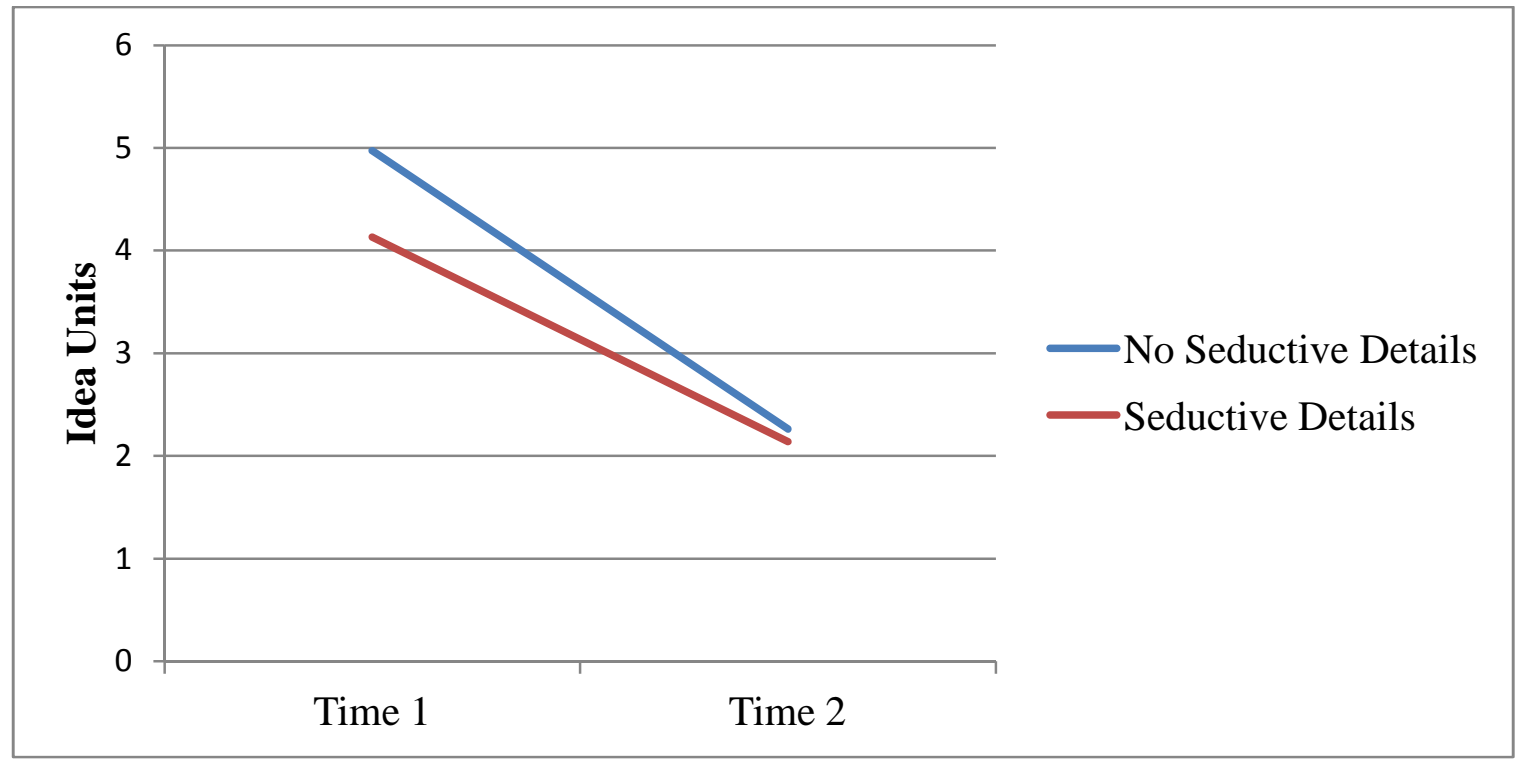

Figure 4: Influence of Seductive Details with Time

The third hypothesis was that repeated testing would enhance memory for new information concerning the paranormal. This was not shown. Instead, the opposite effect was demonstrated, with participants remembering significantly less when tested a second 
time one week after reading their article compared to when they were tested the first time immediately after reading the article, $F(1,173)=10.670, p<.001, \eta_{p}{ }^{2}=.06$ (see Figure 5). For means and standard deviations see table 2.

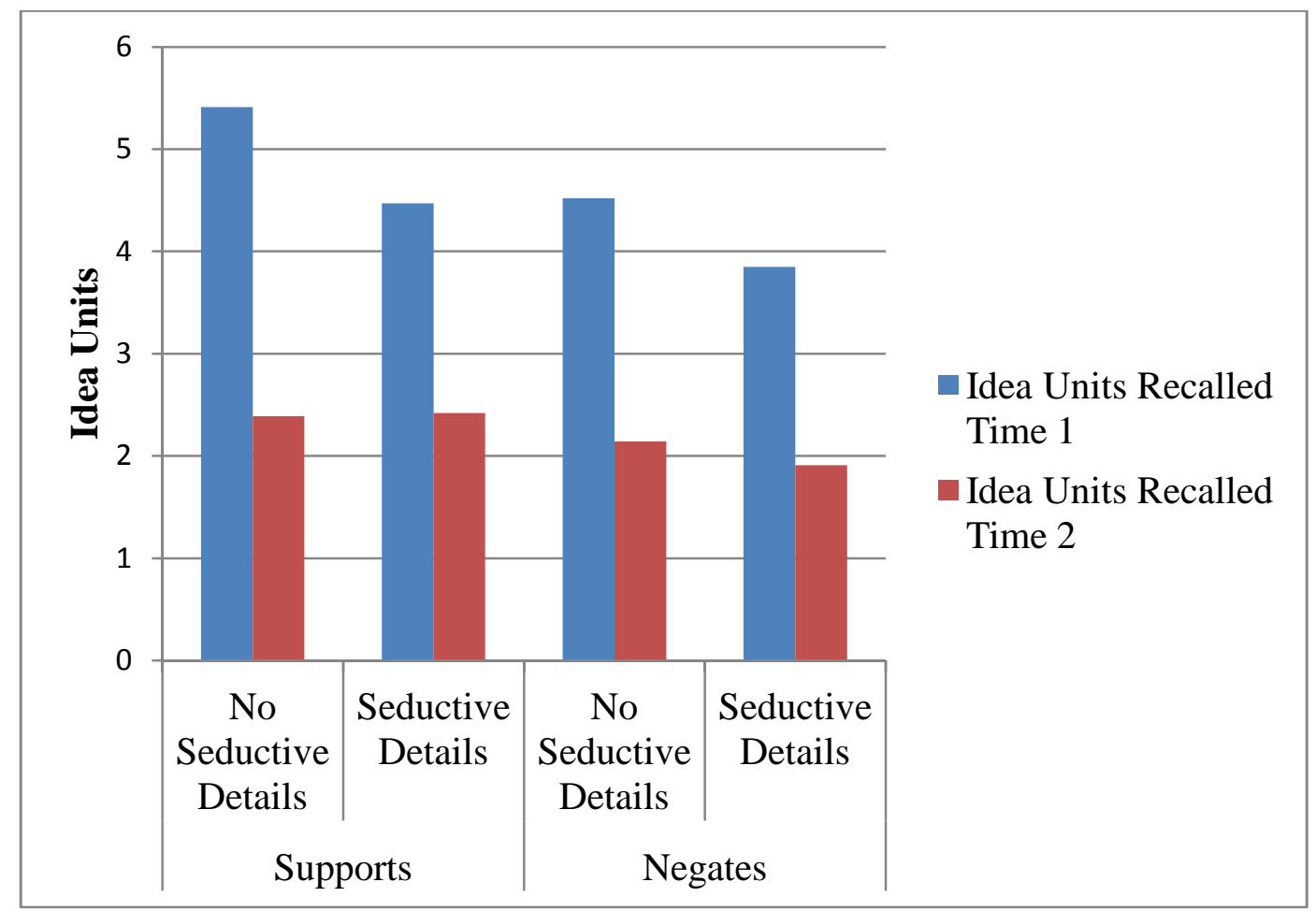

\section{Figure 5: Influence of Time on Recall}

The fourth hypothesis was that believers exposed to belief-incongruent information would experience increased memory intrusions, as would those with more rational thinking styles. However, once more hypotheses pertaining to belief-congruence could not be analyzed due to the normal distribution of R-PBS scores. As for the role of rational thinking style in memory intrusions, none was shown, $F(1,196)=.364, p=.547$, $R^{2}=.002$. Yet, additional analyses did reveal that seductive details led to fewer memory intrusions, $F(1,203)=3.828, p=.052, \eta_{p}{ }^{2}=.019$ (see Figure 6). For means and standard deviations see Table 3 . 
Table 3: Descriptive Statistics for Intrusions, Time 1

\begin{tabular}{|c|c|c|c|c|}
\hline Valence & $\begin{array}{l}\text { Seductive } \\
\text { Details }\end{array}$ & $M$ & $S D$ & $n$ \\
\hline \multirow[t]{6}{*}{ Negative } & No & 4.44 & 2.84 & 48 \\
\hline & Seductive & & & \\
\hline & Details & & & \\
\hline & Seductive & 3.47 & 2.22 & 59 \\
\hline & Details & & & \\
\hline & Total & 3.91 & 2.55 & 107 \\
\hline \multirow[t]{6}{*}{ Positive } & No & 5.35 & 3.57 & 54 \\
\hline & Seductive & & & \\
\hline & Details & & & \\
\hline & Seductive & 4.39 & 3.32 & 46 \\
\hline & Details & & & \\
\hline & Total & 4.91 & 3.48 & 100 \\
\hline \multirow[t]{6}{*}{ Total } & No & 4.92 & 3.263 & 102 \\
\hline & Seductive & & & \\
\hline & Details & & & \\
\hline & Seductive & 3.88 & 2.78 & 105 \\
\hline & Details & & & \\
\hline & Total & 4.39 & 3.07 & 207 \\
\hline
\end{tabular}

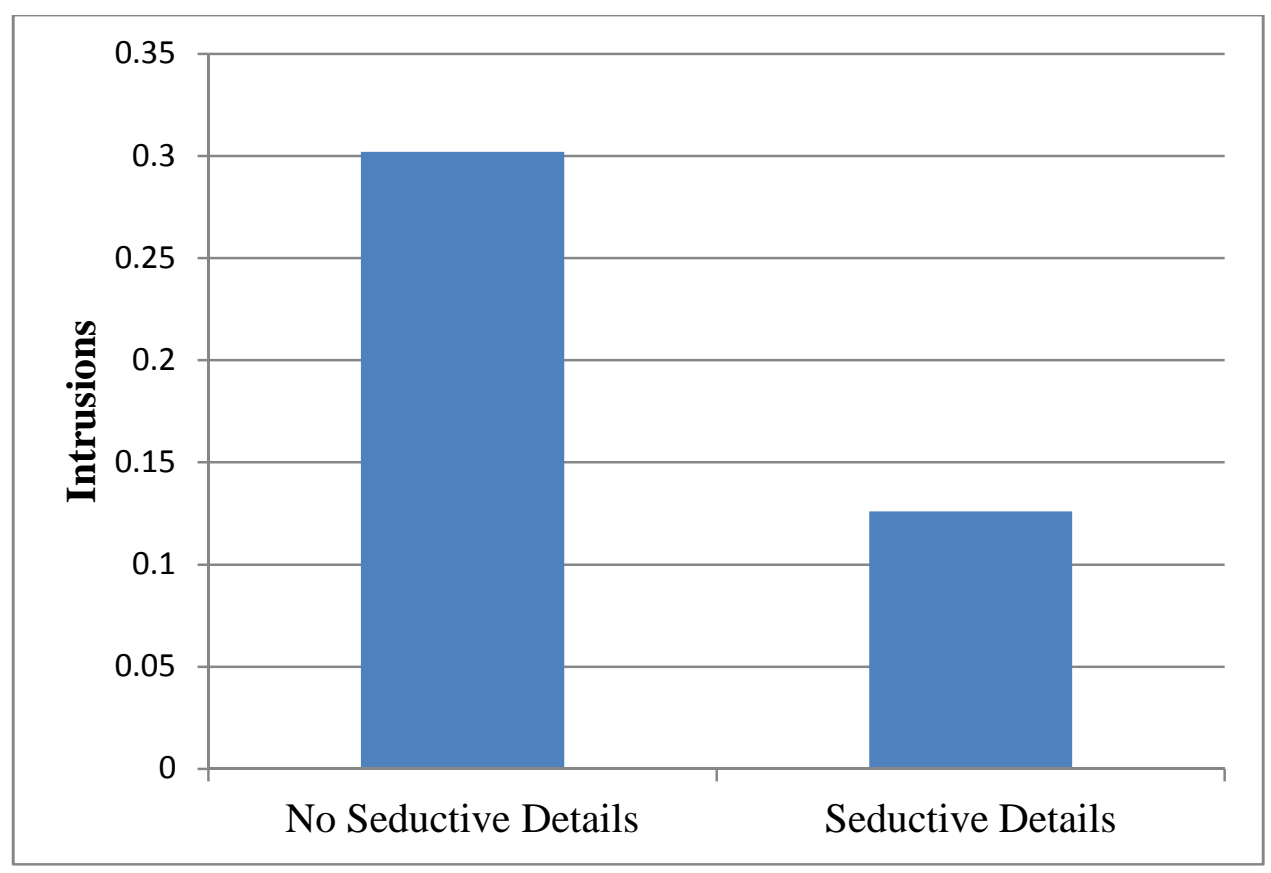

Figure 6: The Influence of Seductive Details on Time 1 Memory Intrusions 
Additionally, article valence was found to influence recall as well, with greater recall occurring when articles were positively valenced, $F(1,207)=4.566, p=.034, \eta_{p}{ }^{2}=$ .022 (see Figure 7). For means and standard deviations, see Table 1.

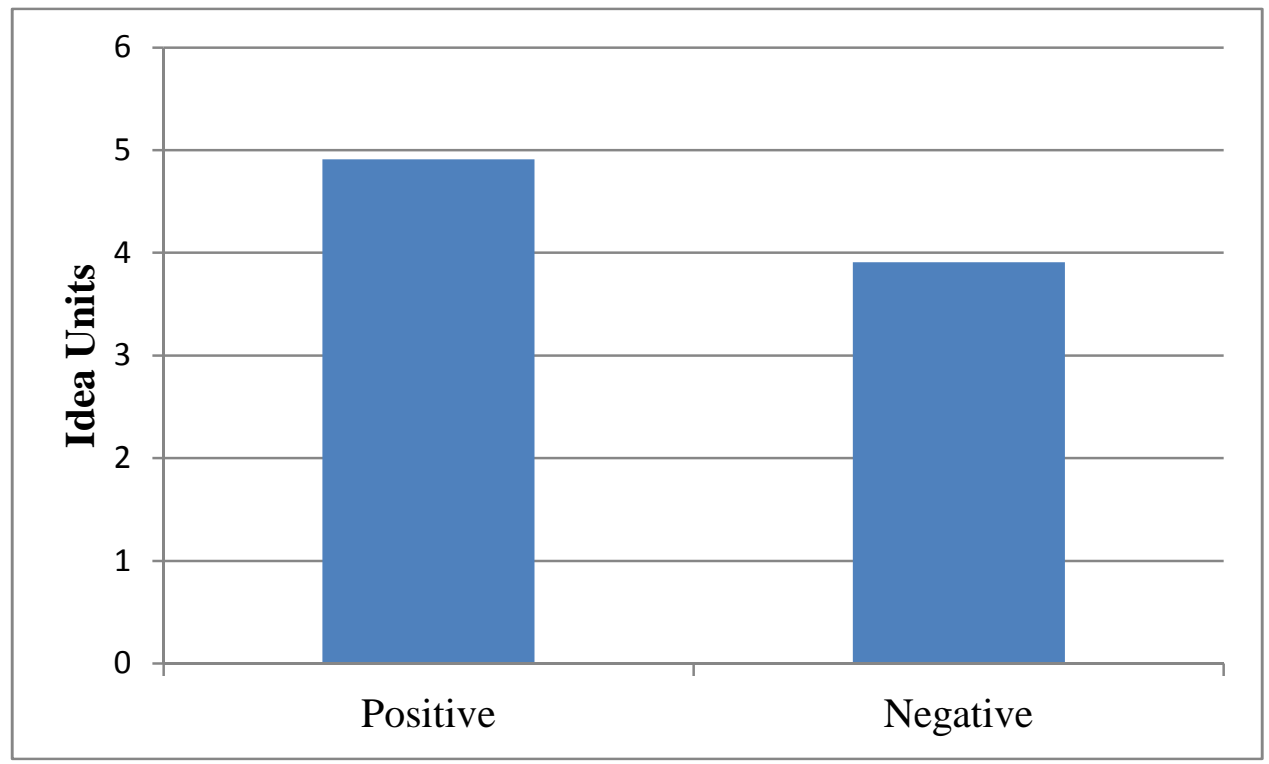

Figure 7: Influence of Valence on Time 1 Recall 


\section{CHAPTER VI \\ DISCUSSION}

\section{Seductive Details}

The strongest finding of the above study was the demonstration that seductive details in the form of superficial neurocognitive information decreased recall for new information when tested immediately after reading that information, but not one week later, with both those who were and were not presented with seductive details remembering equally little after one week. The finding that seductive details decrease recall for new information is consistent with some prior studies (Harp \& Mayer, 1998; Rowland et al. 2008), but not others (Mayer et al., 2008; Rowland et al., 2008). One possible reason for this might be due to the placement of the seductive details within the texts presented to participants, as placement of seductive details has been found to influence their effect. However, according to previous research, seductive details tend to be most damaging if at the beginning of a text, as opposed to at the end (Rowland et al., 2008), which is where the majority of the seductive details were placed in the articles

used in the above study, suggesting their influence may have been even stronger if they appeared earlier in the article.

Furthermore, given the placement of the seductive details in this study, and the finding that they had an effect on recall, it seems more likely that they exerted their effect by disrupting the organization and integration of new information into a coherent mental 
model, as described by Mayer et al. (2008), than by priming participants to organize what they were about to learn around irrelevant prior knowledge, which appears to have occurred in the work of Harp and Mayer (1998). Additionally, it is worth noting that this study not only demonstrated that seductive details reduce memory for the information they are intermixed with, but for false memories, or memory intrusions, as well. One reason for this is that memory intrusions may be inferences stemming from gist memory representations and that if seductive details mitigate the amount of information remembered at the gist level, people may have less internalized information to use when developing false memories. However, whether these intrusions truly did stem from gist memory representations as opposed to verbatim ones is difficult to report with certainty given that efforts were not made to experimentally examine the nature of the intrusions at this level. It is only inferred here that they may stem from gist representations due to the suggestion put forth by Titcomb and Reyna (1995) that gist memories increase false memories based on new information that is inaccurate but consistent with gist representations.

\section{Belief-Congruence}

As for the role of belief-congruence in memory for new information concerning the paranormal, this variable could not properly be evaluated given that the data collected via the R-PBS as a means to initially measure paranormal belief were normally distributed, therefore providing no basis for the use of a median split to divide participants into "believers" and "skeptics," and subsequently those receiving "beliefcongruent" or "belief-incongruent" information. Additionally, when R-PBS scores were 
analyzed as part of an ANCOVA, paranormal belief was not shown to have any influence on recall. Together with the normal distribution of RPBS scores, these findings may provide some reason to call into question what seem like standard practices of performing a median split (Jones \& Russell, 1980; Russell \& Jones, 1980; Wiseman \& Morris, 1995) or using a single Likert question to create quasi-independent variables in this kind of research (Boysen \& Vogel, 2007; Munro 2010).

In the past the creation of such quasi-independent variables through the median split of the total score of a multi-question scale measuring one's level of belief in a given phenomenon has been done in research concerning both paranormal belief (Jones \& Russell, 1980; Russell \& Jones, 1980; Wiseman \& Morris, 1995) and the acceptance of climate change (Corner et al., 2012). Similarly, researchers have derived categorical variables from continuous data by asking participants a relatively small number of direct questions concerning their attitudes or behaviors in relation to a topic, cause, or group to create "pro-", "anti-", and "neutral" categories when researching biased assimilation and attitude polarization when encountering new information about marginalized groups such as homosexuals or the mentally ill, or contentious socio-scientific topics like the development and implementation of nuclear technologies (Boysen \& Vogel, 2007; Boysen \& Vogel, 2008; Munro, 2010; Plous 1991).

However, these methods of creating quasi-independent variables may not always be warranted, especially in the absence of a sufficient number of people with extreme attitudes concerning the topic of interest. Some have even argued that even under such circumstances the dichotomization of a continuous variable is still not warranted due to the resulting loss of information concerning individual differences and linear 
relationships, alterations of effect size and power, and decreases in reliability (MacCullum, Zhang, Preacher, \& Rucker, 2002). Yet, even if these undesirable effects could be shown to be minimal when creating quasi-independent variables in a study of motivated reasoning and biased assimilation, the results yielded from subsequent analyses may still be attenuated if respondents lack conviction in their beliefs or are not personally active in an organization concerned with the topic or cause the newly presented information concerns (Plous, 1991). One potential reason for the attenuation of these effects is that if a topic is of little importance to an individual, a challenge to a belief they may casually hold concerning the topic presumably would not present a challenge to their sense of self, their sense of reality, or their self-esteem, and therefore would fail to produce the heightened emotional arousal described by Russell and Jones (1980) when the beliefs of some participants concerning the paranormal were threatened, the increased activation of areas of the brain associated with pain and punishment demonstrated by Westen et al. (2006) when participants were presented with negative portrayals of favored politicians, or the ego-protective processes hypothesized by Klaczynski and Narasimham (1998).

To cope with these kinds of potential problems, some researchers have consequently directly recruited students at their universities known for their extreme opinions on a topic of interest (Levine \& Murphy, 1943) or targeted organizations likely to attract individuals with extreme opinions (Plous, 1991). For example, when examining biased assimilation and attitude polarization for new information regarding technological breakdowns related to nuclear weapons and energy, Plous sought participants from a population of ROTC cadets, as well as staff members of the peace organizations Beyond 
War and Physicians for Social Responsibility. Considering that the standard college sample used in the study reported here yielded such normally distributed levels of paranormal belief as discerned from the collected R-PBS scores, it may be worthwhile for future researchers to seek out individuals with more extreme opinions concerning the paranormal such as attendees of a skeptic's meetup or paranormal convention when evaluating the role of paranormal belief in recall for belief-congruent and beliefincongruent information concerning the paranormal.

\section{Repeated Testing}

A less surprising finding was that contrary to initial predictions, recall significantly declined between testing at time one immediately after reading the article and at time two one week later. In retrospect, unlike the studies that informed the prediction that repeated testing would lead to better recall (Dunlosky et al., 2010; Roediger \& Karpicke, 2006), participants, despite being told to read the article they were given, were never explicitly told to study it or given any indication that they would be asked about it in the future. However, once more, the reason for not doing so was to attempt to create a fairly realistic scenario in which a person casually reads an article or blog post, and then is asked about it by a friend or colleague upon finishing, and again one week later.

\section{Memory Intrusions}

With regard to memory intrusions, the only factor that seemed to influence their occurrence was that of seductive details, which led to a decrease in their frequency. 
Paranormal belief had no effect on memory intrusions, possibly because of the lack of participants with high levels of belief in the sample that was used. Rationality scores did not have an effect on memory intrusions either, however it should be noted that a number of participants only answered using the extreme ends of the Likert scale when filling out the REI. When this was first noticed well into the process of collecting data, an examination of the wording of the instructions for filling out the REI revealed some ambiguity in whether those filling it out should treat individual questions as dichotomous or continuous. Although the majority of participants correctly treated the questions as continuous, if enough of them treated the questions as dichotomous, this may have had an impact on analyses involving this measure.

\section{Valence}

Initially, article valence was not a variable intended to be examined directly through this study, but to aid in determining the influence of belief-congruence. However, because levels of belief in the paranormal were normally distributed within our sample, this could not be done. Nevertheless, valence was analyzed and was shown to have an influence on recall with positively valenced articles eliciting greater recall than negatively valenced ones.

Although it does not appear the effects of valence have been studied much in the context of memory for potentially controversial information, studies pertaining to the interpretation of new scientific information have shown that despite being able to distinguish between an accurate scientific finding and an inaccurate scientific finding with some level of accuracy (Richard, Bond, \& Stokes-Zoota, 2001), the majority of 
people will tend to agree with statements they read as true, that knowledge of the outcome of a study increases perceptions of an outcome's obviousness, that people will rate practically any reasonable statement as obvious, that people will not always reliably choose an actual finding over its opposite, and that people tend to rate findings they choose over alternatives as more obvious regardless of whether they are right or wrong (Gage, 1991; Wong, 1996). Furthermore, it appears that there is a more general trend across different bodies of research suggesting that negatively valenced words and statements are more difficult to process at least in some contexts (Gotoh, Kikuchi, \& Olofsson, 2010; Macbeth et al., 2014), with researchers suggesting that mere comprehension of a statement leads to its subsequent acceptance, and that its rejection requires an additional process (Harris et al., 2008), thus resulting in the observed influence of valence on cognitive functioning.

\section{General Discussion}

Once more the most prominent findings of this study concerned the influence of seductive details. Here they were found to decrease recall when memory was tested immediately after the presentation of the new information accompanied by seductive details. However, the effect was no longer present one week later. Additionally, the presence of seductive details also reduced the number of memory intrusions reported by participants.

As for the effects of belief-congruence and retesting on memory for new information concerning the paranormal, and rational thinking style on memory intrusions, no significant results were found, potentially due to some of the issues discussed above. 
Belief-congruence could not be properly evaluated due to the lack of participants with extreme opinions concerning the existence of paranormal phenomena. In an attempt to create a realistic scenario, participants were told to read, but not told to study, the information they were presented with. The wording of the scale measuring thinking style may have misled some participants to fill it out as if its questions were dichotomous as opposed to continuous. However, there are also some more general concerns pertaining to the study as a whole.

As with many psychological studies, there are questions regarding how representative a sample of largely white, female, psychology majors in their late teens and early twenties truly is of the larger population. In recent years, this common practice of generalizing from such a subpopulation of Western, educated, industrialized, rich, democratic societies by social and cognitive scientists has been called into question (Henrich, Heine, \& Norenzayan, 2010). Also, effect sizes for the findings reported in this study tended to be small, making the large number of participants whose data needed to be excluded from analyses due to failure to properly fill out the R-PBS, read the article, or show up for time two even more unfortunate. Whether these problems with participants were due to the procedure of filling out two surveys, reading an article, and doing a free recall task being too tedious for some participants, whether they found the topic to be of no interest to them, or whether these participants just did not care or take the task seriously remains unknown. Another possibility is that since students were allowed to work through the tasks at their own rate in a group setting, some may have felt pressured to keep up with those that finished most quickly, even though these students 
may have remembered the least amount of information or may have rushed through the task.

In performing future studies, it would be wise to attempt to better control for or reduce some of the basic methodological concerns described above. However, there are four directions for future studies that I believe could potentially be far more enlightening, assuming the basic methodological problems could be effectively dealt with. The first would be to examine the effect of the placement of seductive details in the articles on memory, given that the findings reported here are consistent with one of the standard effects of seductive details (Harp \& Mayer, 1998), although not the with later studies that examined the role of their placement more closely (Roland et al., 2008). The second would be to use a continuous, multi-question measure such as the R-PBS in a study of motivated reasoning as opposed to the more standard two or three direct questions used in those types of studies. The third would be to conduct the same study as that which was performed here, but, when doing so, encourage students to study the text they receive as opposed to just reading it. The fourth would be to conduct the study performed here, as well as those suggested in this paragraph, using samples of more extreme skeptics and believers. 


\section{REFERENCES}

Anderson, C. A., Lepper, M., \& Ross, L. (1980). Perseverance of social theories: the role of explanation in the persistence of discredited information. Journal of Personality and Social Psychology, 39, 6, 1037-1049.

Bastardi, A., Uhlmann, E. L., \& Ross, L. (2011). Wishful thinking: belief, desire, and the motivated evaluation of scientific evidence, Psychological Science 22, 6, 731-732.

Berkowitz, S. R., Laney, C., Morris, M. G., \& Loftus, E. F. (2008). Pluto behaving badly: false beliefs and their consequences. The American Journal of Psychology, 121, 4, 643-660.

Bernstein, D. M. \& Loftus, E. F. (2009). The consequences of false memories for food preferences and choices. Perspectives on Psychological Science, 4, 2, 135-139.

Blank, H. (2009). Remembering: a theoretical interface between memory and social psychology. Social Psychology, 40, 3, 164-175.

Boysen, G. A. \& Vogel, D. L. (2007). Biased assimilation and attitude polarization in response to learning about biological explanations of homosexuality. Sex Roles, $57,755-762$.

Boysen, G. A. \& Vogel, D. L. (2008). Education and mental health stigma: the effects of attribution, biased, assimilation, and attitude polarization. Journal of Social and Clinical Psychology, 25, 5, 447-470.

Corner, A., Whitmarsh, L., \& Xenias, D. (2012). Uncertainty, skepticism and attitudes towards climate change: biased assimilation and attitude polarization. Climatic Change, 114, 463-478.

Desjardins, T. \& Scoboria, A. (2007). "You and your best friend Suzy put slime in Ms. Smollett's desk": producing false memories with self-relevant details. Psychonomic Bulletin and Review, 14, 6, 1090-1095.

Dunlosky, J., Hartwig, M. K., Rawson, K. A., \& Lipko, A. R. (2010). Improving college students' evaluation of text learning using idea-unit standards. The Quarterly Journal of Experimental Psychology, 64, 3, 467-484.

Epstein, S. (1994). Integration of the cognitive and the psychodynamic unconscious. 
American Psychologist, 49, 8, 709-724.

Frenda, S. J., Knowles, E. D., Saletan, W., \& Loftus, E. F. (2013). False memories of fabricated political events. Journal of Experimental Psychology, 49, 280-286.

Gotoh, F., Kikuchi, T., \& Olofsson, U. (2010). A facilitative effect of negative affective valence on working memory. Scandanavian Journal of Psychology, 51, 185-191.

Harp, S. F. \& Mayer, R. E. (1998). How seductive details do their damage: A theory of cognitive interest in science learning. Journal of Educational Psychology, 90, 3, 414-434.

Harris, S., Sheth, S. A., \& Cohen, M. S. (2007). Functional neuroimaging of belief, disbelief, and uncertainty. Annals of Neurology, 63, 2, 141-147.

Harris, S., Kaplan, J. T., Curiel, A., Bookheimer, S. Y., Iacoboni, M., \& Cohen, M.S. (2009) The neural correlates of religious and nonreligious belief. PLoS ONE, 4, $10,1-9$.

Hastorf, A. H. \& Cantril, H. (1954). They saw a game: A case study. The Journal of Abnormal and Social Psychology, 49, 1, 129-134.

Jones, W. H. \& Russell, D. (1980). The selective processing of belief disconfirming information. European Journal of Social Psychology, 10, 309-312.

Kahneman, D. (2011). Thinking, Fast and Slow. New York: Farrar, Straus and Giroux.

Klaczynski, P.A., \& Narasimham, G. (1998). Development of scientific reasoning biases: cognitive versus ego-protective explanations. Developmental Psychology, 34, 1, pp 175-187.

Klaczynski, P. A. \& Robinson, B. (2000). Personal theories, intellectual ability, and epistemological beliefs: adult age differences in everyday reasoning biases. Psychology and Aging, 15, 3, 400-416.

Kuhn, D. (1989). Children and adults as intuitive scientists. Psychological Review, 96, 4, 674-689.

Leding, J. K. (2011) Need for cognition and false recall. Personality and Individual Differences, 51, 68-72.

Levine, J.M., \& Murphy, G. (1943). The learning and forgetting of controversial material. Journal of Abnormal and Social Psychology, 38, 507-517.

Lord, C. G., Lepper, M. R., \& Preston, E. (1984). Considering the opposite: a corrective strategy for social judgment. Journal of Personality and Social Psychology, 47, 6, 
1231-1243.

Lord, C. G., Ross, L., \& Lepper, M. (1979). Biased assimilation and attitude polarization: the effects of prior theories on subsequently considered evidence. Journal of Personality and Social Psychology, 37, 11, 2098-2109.

Macbeth, G., Razumiejczyk, E., del Carmen Crivello, M., Bolzan, C., Girardi, C. I. P., Campitelli, G. (2014). Mental models for the negation of conjunctions and disjunctions. Europe's Journal of Psychology, 10, 1, 135-149.

MacCallum, R. C., Zhang, S., Preacher, K. J., \& Rucker, D. D. (2002). On the practice of dichotomization of quantitative variables. Psychological Methods, 7, 1, 19

Masnick, A. M., \& Zimmerman, C. (2009). Evaluating scientific research in the context of prior belief: hindsight bias or confirmation bias?. Journal of Psychology of Science and Technology, 2, 1, 29-36.

Mayer, R. E., Griffith, E., Jurkowitz, I. T. N., \& Rothman, D. (2008). Increased interestingness of extraneous details in multimedia science presentation leads to decreased learning. Journal of Experimental Psychology: Applied. 14, 4, 329-339.

Munro, G. D., Leary, S. P, Lasane., T. P. (2004). Between a rock and a hard place: biased assimilation of scientific information in the face of commitment. North American Journal of Psychology, 6, 3, 431-444.

Munro, G. (2010). The scientific impotence excuse: discounting belief-threatening scientific abstracts. Journal of Applied Psychology, 40, 3, 579-600.

Pacini, R. \& Epstein, S. (1999). The relation of rational and experiential information processing styles to personality, basic beliefs, and the ratio-bias phenomenon. Personality Processes and Individual Differences, 76, 6, 972-987.

Plous, S. (1991). Biases in the assimilation of technological breakdowns: do accidents make us safer? Journal of Applied Social Psychology, 21, 13, 1058-1082.

Reich, D. A, Green, M., Brock, T., \& Tetlock, P. (2006). Biases in research evaluation: inflated assessment, oversight, or error-type weighting?. Journal of Experimental Social Psychology, 43, 663-640.

Roediger, H. L. \& Karpicke, J. D. (2006). Test-enhanced learning: taking memory tests improves long-term retention. Psychological Science, 17, 3, 249-255.

Rowland, E., Skinner, C. H., Davis-Richards, K., Saundargas, D. H., \& Robinson, D. H. (2008). An investigation of placement and type of seductive details: the primacy effect of seductive details on text recall. Research in the Schools, 15, 2, 80-90. 
Russell, D. \& Jones, W. H. (1980). When superstition fails: Reactions to disconfirmation of paranormal beliefs. Personality and Social Psychology Bulletin, 6, 1, 83-88.

Sacchi, D. L. M., Agnoli, F., \& Loftus, E. F. (2007). Changing history: doctored photographs affect memory for past public events. Applied Cognitive Psychology, 21, 1005-1022.

Shermer, M. (2011). The Believing Brain: From Ghosts and Gods to Politics and Conspiracies - How We Construct Beliefs and Reinforce Them as Truths. New York: Time Books, Henry, Holt and Company.

Sloman, S. A. The empirical case for two systems or reasoning. Psychological Bulletin, $119,1,3-22$.

Strange, D., Hayne, H., Garry, M. (2008). A photo, a suggestion, a false memory. Applied Cognitive Psychology, 22, 587-603.

Titcomb, A. L., \& Reyna, V. F. (1995). Memory interference and misinformation effects. In F. N. Dempster \& C. J. Brainderd (Eds.), Interference and Inhibition in Cognition (pp. 263-294). San Diego CA: Academic Press.

Tobacyk, J. \& Milford, G. (1983). Belief in paranormal phenomena: assessment instrument development and implications for personality functioning. Journal of Personality and Social Psychology, 44, 5, 1029-1037.

Tobacyk, J. J. (2004). A revised paranormal belief scale. The International Journal of Transpersonal Studies, 23, 94-98.

Tversky, A. \& Kahneman, D. (1974). Judgement under uncertainty: heuristics and biases. Science, 185, 4175, 1124-1131.

Wade, K. A., Garry, M., Read, J. D., \& Lindsay, S. (2002). A picture is worth a thousand lies: using false photographs to create false childhood memories. Psychonomic Bulletin and Review, 9, 3, 597-603.

Weisberg, D. S., Keli, F. M., Goodstein, J., Rawson, E., \& Gray, J. (2008). The seductive allure of neuroscience explanations. Journal of Cognitive Neuroscience, 20, 3 , 440-447.

Westen, D., Blagov, P. S., Harenski, K., Kilts, C., \& Hamann, S. (2006). Neural bases of motivated reasoning: an fMRI study of emotional constraints on partisan political judgment in the 2004 U.S. presidential election. Journal of Cognitive Neuroscience, 8, 11, 1947-1958.

Wiley, J. A fair and balanced look at the news: what affects memory for controversial arguments? Journal of Memory and Language, 53, 95-109. 
Wilson, T. D., DePaulo, B., Mook, D., \& Klaaren, K. (1993). Scientists' evaluations of research: the biasing effects of the importance of the topic. Psychological Science, $4,5,322-325$.

Wiseman, R. \& Morris, M. L. (1995). Recalling pseudo-psychic demonstrations. British Journal of Psychology, 86, 112-125.

Zeigler, D. L., Walker, K. A, Ackett, W. A., \& Simmons, M. L. (2002). Tangled up in views: beliefs in the nature of science and responses to socioscientific dilemmas. Science Education, 86, 343-367. 


\section{APPENDIX A}

REVISED PARANORMAL BELIEF SCALE (R-PBS; TOBACYK, 2004)

\section{Revised Paranormal Belief Scale}

Please put a number next to each item to indicate how much you agree or disagree with that item. Use the numbers as indicated below. There are no right or wrong answers. This is a sample of your own beliefs and attitudes. Thank you.

1=Strongly Disagree 2=Moderately Disagree 3=Slightly Disagree

4=Uncertain 5=Slightly Agree 6=Moderately Agree 7=Strongly Agree

1. The soul continues to exist though the body may die.

2. Some individuals are able to levitate (lift) objects through mental forces.

3. Black magic really exists.

4. Black cats can bring bad luck.

5. Your mind or soul can leave your body and travel (astral projection).

6. The abominable snowman of Tibet exists.

7. Astrology is a way to accurately predict the future.

8. There is a devil.

9. Psychokinesis, the movement of objects through psychic powers, does exist.

10. Witches do exist.

11. If you break a mirror, you will have bad luck.

12. During altered states, such as sleep or trances, the spirit can leave the body.

13. The Loch Ness monster of Scotland exists.

14. The horoscope accurately tells a person's future.

15. I believe in God

16. A person's thoughts can influence the movement of a physical object.

17. Through the use of formulas and incantations, it is possible to cast spells on persons.

18. The number " 13 " is unlucky.

19. Reincarnation does occur.

20. There is life on other planets.

21. Some psychics can accurately predict the future.

22. There is a heaven and a hell.

23. Mind reading is not possible.

24 . There are actual cases of witchcraft.

25. It is possible to communicate with the dead.

26. Some people have an unexplained ability to predict the future. 
Note. Item 23 is reverse scored. Traditional Religious Belief = Mean of Items $(1,8,15$, 22);

Psi $=$ Mean of Items (2, 9, 16, 23); Witchcraft $=$ Mean of Items (3, 10, 17, 24);

Superstition = Mean of Items (4, 11, 18); Spiritualism = Mean of Items $(5,12,19,25)$

Extraordinary Life Forms = Mean of Items (6, 13, 20); Precognition = Mean of Items (7,

$14,21,26)$. 


\title{
APPENDIX B
}

\section{RATIONAL EXPERIENTIAL INVENTORY (REI; PACINI \& EPSTEIN, 1999)}

\author{
$1=$ Definitely Not True of Myself, 5 = Definitely True of Myself
}

1. I try to avoid situations that require thinking in depth about something.

2. I'm not that good at figuring out complicated problems.

3. I enjoy intellectual challenges.

4. I am not very good at solving problems that require careful logical analysis.

5. I don't like to have to do a lot of thinking.

6. I enjoy solving problems that require hard thinking.

7. Thinking is not my idea of an enjoyable activity.

8. I am not a very analytical thinker.

9. Reasoning things out carefully is not one of my strong points.

10. I prefer complex problems to simple problems.

11. Thinking hard and for a long time about something gives me little satisfaction.

12. I don't reason well under pressure.

13. I am much better at figuring things out logically than most people.

14. I have a logical mind.

15. I enjoy thinking in abstract terms.

16. I have no problem thinking things through carefully.

17. Using logic usually works well for me in figuring out problems in my life.

18. Knowing the answer without having to understand the reasoning behind it is good enough for me.

19. I usually have clear, explainable reasons for my decisions.

20. Learning new ways to think would be very appealing to me.

21 . I like to rely on my intuitive impressions.

22. I don't have a very good sense of intuition.

23. Using my gut feelings usually works well for me in figuring out problems in my life.

24. I believe in trusting my hunches.

25 . Intuition can be a very useful way to solve problems.

26. I often go by my instincts when deciding on a course of action.

27. I trust my initial feelings about people.

28 . When it comes to trusting people, I can usually rely on my gut feelings.

29. If I were to rely on my gut feelings, I would often make mistakes.

30. I don't like situations in which I have to rely on intuition.

31. I think there are times when one should rely on one's intuition.

32. I think it is foolish to make important decisions based on feelings.

33. I don't think it is a good idea to rely on one's intuition for important decisions. 
34. I generally don't depend on my feelings to help me make decisions.

35. I hardly ever go wrong when I listen to my deepest gut feelings to find an answer.

36. I would not want to depend on anyone who described himself or herself as intuitive.

37. My snap judgments are probably not as good as most people's.

38. I tend to use my heart as a guide for my actions.

39. I can usually feel when a person is right or wrong, even if I can't explain how I know.

40. I suspect my hunches are inaccurate as often as they are accurate. 


\section{APPENDIX C \\ SUPPORTS WITHOUT NEUROCOGNITIVE JARGON}

Reprinted with permission from Science \& Technology News Weekly, August 6, 2011 RESEARCH NEWS

\section{REPORT SUPPORTS CLAIMS OF PARANORMAL PHENOMENA}

(UPI) A report recently released by The Oxford Institute of Consciousness Studies indicates that paranormal phenomena are not only real, but that researchers would be wise to consider such lines of inquiry as we move further into the twenty first century. In a comprehensive review of experiments from over 100 universities and research centers, it was reported that over 300 recent studies conducted since 2009 support claims of the paranormal. Among the phenomena supported are ESP, collective consciousness, and out of body experiences. Director of the National Institutes of Health, Francis Collins, called the report "A convincing review supporting the supernatural as legitimate scientific research."

Among the most significant findings the review reported are:

Participants knowing when a friend in another room was thinking about them;

The psychic transmission of mental images of photographs and video images to individuals in another room;

The validity of out of body experiences.

According to the Institute's report, the studies examined were methodologically sound, well controlled, and had statistically significant findings when the proper analyses were performed. The report's head author, Dr. Randy Weiss, sympathized with skeptics of paranormal research, but concluded "Although some would like to think that such phenomena are not possible, current research suggests otherwise."

2011 United Features Syndicate 
APPENDIX D

REFUTES WITHOUT NEUROCOGNITIVE JARGON

Reprinted with permission from Science \& Technology News Weekly, August 6, 2011 RESEARCH NEWS

\section{REPORT REFUTES CLAIMS OF PARANORMAL PHENOMENA}

(UPI) A report recently released by The Oxford Institute of Consciousness Studies indicates that paranormal phenomena are not only false, but that researchers would be foolish to consider such lines of inquiry as we move further into the twenty first century. In a comprehensive review of experiments from over 100 universities and research centers, it was reported that over 300 recent studies conducted since 2009 refute claims of the paranormal. Among the phenomena refuted are ESP, collective consciousness, and out of body experiences. Director of the National Institutes of Health, Francis Collins, called the report "A convincing review refuting the supernatural as legitimate scientific research."

Among the most significant phenomena the review discredited are:

Participants knowing when a friend in another room was thinking about them;

The psychic transmission of mental images of photographs and video images to individuals in another room;

The validity of out of body experiences.

According to the Institute's report, the studies examined were methodologically sound, well controlled, and had statistically significant findings when the proper analyses were performed. The report's head author, Dr. Randy Weiss, sympathized with proponents of paranormal research, but concluded "Although some would like to think that such phenomena are possible, current research suggests otherwise."

2011 United Features Syndicate 


\section{APPENDIX E}

\section{SUPPORTS WITH NEUROCOGNITIVE JARGON}

Reprinted with permission from Science \& Technology News Weekly, August 6, 2011 RESEARCH NEWS

\section{REPORT SUPPORTS CLAIMS OF PARANORMAL PHENOMENA}

(UPI) A report recently released by The Oxford Institute of Neurocognitive Studies indicates that paranormal phenomena are not only real, but that researchers would be wise to consider such lines of inquiry as we move further into the twenty first century. In a comprehensive review of experiments from over 100 universities and research centers, it was reported that over 300 recent studies conducted since 2009 support claims of the paranormal. Among the phenomena supported are ESP, quantum consciousness, and out of body experiences. Director of the National Institutes of Health, Francis Collins, called the report "A convincing review supporting the supernatural as legitimate scientific research."

Among the most significant findings the review reported are:

Participants synchronizing their brainwaves with those of a friend in another room;

The psychic transmission of mental images of photographs and video images to individuals in another room through the activation of the receiver's occipital cortex;

The separation of consciousness from the brain during out of body experiences.

The studies examined looked at increases in event related potentials in neurons, elevated baseline $\alpha$-waves, and increased activity in the Shaw nucleus of the anterior cingulate when alleged paranormal phenomena were being tested. According to the Institute's report, these studies were methodologically sound, well controlled, and had statistically significant findings when the proper analyses were performed. The report's head author, Dr. Randy Weiss, sympathized with skeptics of paranormal research, but concluded "Although some would like to think that such phenomena are not possible, current research suggests otherwise." 


\section{APPENDIX F}

\section{REFUTES WITH NEUROCOGNITIVE JARGON}

Reprinted with permission from Science \& Technology News Weekly, August 6, 2011 RESEARCH NEWS

\section{REPORT REFUTES CLAIMS OF PARANORMAL PHENOMENA}

(UPI) A report recently released by The Oxford Institute of Neurocognitive Studies indicates that paranormal phenomena are not only false, but that researchers would be foolish to consider such lines of inquiry as we move further into the twenty first century. In a comprehensive review of experiments from over 100 universities and research centers, it was reported that over 300 recent studies conducted since 2009 refute claims of the paranormal. Among the phenomena refuted are ESP, quantum consciousness and out of body experiences. Director of the National Institutes of Health, Francis Collins, called the report "A convincing review refuting the supernatural as legitimate scientific research."

Among the most significant phenomena the review discredited are:

Participants synchronizing their brainwaves with those of a friend in another room;

The psychic transmission of mental images of photographs and video images to individuals in another room through the activation of the receiver's occipital cortex;

The separation of consciousness from the brain during out of body experiences.

The studies examined looked at increases in event related potentials in neurons, elevated baseline $\alpha$-waves, and increased activity in the Shaw nucleus of the anterior cingulate when alleged paranormal phenomena were being tested. According to the Institute's report, these studies were methodologically sound, well controlled, and had statistically significant findings when the proper analyses were performed. The report's head author, Dr. Randy Weiss, proponents of paranormal research, but concluded "Although some would like to think that such phenomena are possible, current research suggests otherwise."

2011 United Features Syndicate 


\section{APPENDIX G}

\section{SUPPORTS WITHOUT NEUROCOGNITIVE JARGON (WITH IDEA UNITS)}

Reprinted with permission / from Science \& Technology News Weekly, / August 6, 2011 / RESEARCH NEWS

\section{REPORT SUPPORTS CLAIMS / OF PARANORMAL PHENOMENA}

(UPI) / A report recently released / by The Oxford Institute of Consciousness Studies / indicates that paranormal phenomena are not only real, / but that researchers would be wise to consider / such lines of inquiry / as we move further into the twenty first century. / In a comprehensive review / of experiments / from over 100 universities / and research centers, / it was reported / that over 300 recent studies / conducted since 2009 / support claims of the paranormal. / Among the phenomena supported / are ESP, / collective consciousness, / and out of body experiences. / Director of the National Institutes of Health, / Francis Collins, / called the report / "A convincing review / supporting the supernatural / as legitimate scientific research."

/Among the most significant findings the review reported are: /

Participants knowing / when a friend / in another room / was thinking about them;

The psychic transmission / of mental images / of photographs / and video images / to individuals / in another room;

The validity of out of body experiences.

According to the Institute's report, / the studies examined were / methodologically sound, / well controlled, / and had statistically significant findings / when the proper analyses were performed. / The report's head author, / Dr. Randy Weiss, / sympathized with skeptics of paranormal research, / but concluded /"Although some would like to think / that such phenomena are not possible, / current research suggests otherwise."

2011 / United Features Syndicate 


\section{APPENDIX H}

\section{REFUTES WITHOUT NEUROCOGNITIVE JARGON (WITH IDEA UNITS)}

Reprinted with permission from Science \& Technology News Weekly, August 6, 2011 RESEARCH NEWS

\section{REPORT REFUTES CLAIMS / OF PARANORMAL PHENOMENA}

(UPI) / A report recently released / by The Oxford Institute of Consciousness Studies / indicates that paranormal phenomena are not only false,/ but that researchers would be foolish to consider / such lines of inquiry / as we move further into the twenty first century. / In a comprehensive review / of experiments from over 100 universities / and research centers, / it was reported / that over 300 recent studies / conducted since 2009 / refute claims of the paranormal. / Among the phenomena refuted / are ESP, / collective consciousness, / and out of body experiences. / Director of the National Institutes of Health, / Francis Collins, / called the report / "A convincing review / refuting the supernatural / as legitimate scientific research."

/Among the most significant phenomena the review discredited are:/

Participants knowing / when a friend / in another room / was thinking about them;

The psychic transmission/ of mental images /of photographs/ and video images/ to individuals / in another room;

The validity of out of body experiences.

According to the Institute's report,/ the studies examined were / methodologically sound, /well controlled, /and had statistically significant findings/ when the proper analyses were performed./ The report's head author,/ Dr. Randy Weiss, /sympathized with proponents of paranormal research,/ but concluded/ "Although some would like to think/ that such phenomena are possible,/ current research suggests otherwise."

2011/ United Features Syndicate 


\section{APPENDIX I}

\section{SUPPORTS WITH NEUROCOGNITIVE JARGON (WITH IDEA UNITS)}

Reprinted with permission from Science \& Technology News Weekly, August 6, 2011 RESEARCH NEWS

\section{REPORT SUPPORTS/ CLAIMS OF PARANORMAL PHENOMENA}

(UPI)/ A report recently released/ by The Oxford Institute of Neurocognitive Studies/ indicates that paranormal phenomena are not only real,/ but that researchers would be wise/ to consider such lines of inquiry/ as we move further into the twenty first century. / In a comprehensive review / of experiments/ from over 100 universities/ and research centers,/ it was reported/ that over 300 recent studies/ conducted since 2009/ support claims of the paranormal./ Among the phenomena supported/ are ESP,/ quantum consciousness,/ and out of body experiences. Director of the National Institutes of Health,/ Francis Collins,/ called the report/ "A convincing review/ supporting the supernatural/ as legitimate scientific research."

/Among the most significant findings the review reported are:/

Participants synchronizing their brainwaves/ with those of a friend/ in another room;

The psychic transmission/ of mental images/ of photographs/ and video images/ to individuals/ in another room/ through the activation/ of the receiver's occipital cortex;

The separation of consciousness/ from the brain/ during out of body experiences.

The studies examined looked at/ increases in event related potentials/ in neurons,/ elevated baseline $\alpha$-waves,/ and increased activity in the Shaw nucleus/ of the anterior cingulate/ when alleged paranormal phenomena were being tested./ According to the Institute's report,/ these studies were/ methodologically sound,/ well controlled,/ and had statistically significant findings/ when the proper analyses were performed./ The report's head author,/ Dr. Randy Weiss,/ sympathized with skeptics of paranormal research,/ but concluded/ "Although some would like to think/ that such phenomena are not possible,/ current research suggests otherwise."

2011/ United Features Syndicate 


\section{APPENDIX J}

\section{REFUTES WITH NEUROCOGNITIVE JARGON (WITH IDEA UNITS)}

Reprinted with permission/ from Science \& Technology News Weekly,/ August 6, 2011/ RESEARCH NEWS

\section{REPORT REFUTES CLAIMS/ OF PARANORMAL PHENOMENA}

(UPI)/ A report recently released/ by The Oxford Institute of Neurocognitive Studies/ indicates that paranormal phenomena are not only false,/ but that researchers would be foolish to consider/ such lines of inquiry/ as we move further into the twenty first century./ In a comprehensive review/ of experiments/ from over 100 universities/ and research centers,/ it was reported/ that over 300 recent studies/ conducted since 2009/ refute claims of the paranormal./ Among the phenomena refuted/ are ESP,/ quantum consciousness/ and out of body experiences./ Director of the National Institutes of Health,/ Francis Collins,/ called the report/ "A convincing review/ refuting the supernatural/ as legitimate scientific research."

Among the most significant phenomena the review discredited are:

Participants synchronizing their brainwaves/ with those of a friend/ in another room;

The psychic transmission/ of mental images/ of photographs/ and video images/ to individuals/ in another room/ through the activation/ of the receiver's occipital cortex;

The separation of consciousness/ from the brain/ during out of body experiences.

The studies examined looked at/ increases in event related potentials/ in neurons,/ elevated baseline $\alpha$-waves,/ and increased activity in the Shaw nucleus/ of the anterior cingulate/ when alleged paranormal phenomena were being tested./ According to the Institute's report,/ these studies were/ methodologically sound,/ well controlled,/ and had statistically significant findings/ when the proper analyses were performed./ The report's head author,/ Dr. Randy Weiss,/ sympathized with proponents of paranormal research,/ but concluded/ "Although some would like to think/ that such phenomena are possible,/ current research suggests otherwise."

2011/ United Features Syndicate 